\title{
COLORADOSCHOOLOFMINES
}

EARTH•ENERGY•ENVIRONMENT

Division of ECONOMICS AND BUSINESS

WORKING PAPER SERIES

\section{Renewable Electricity Policies, Heterogeneity, and Cost Effectiveness}

Harrison Fell

Joshua Linn

\author{
Working Paper 2012-07 \\ http: //econbus.mines . edu/working-papers/wp201207.pdf \\ Colorado School of Mines \\ Division of Economics and Business \\ 1500 Illinois Street \\ Golden, CO 80401
}

August 2012

(c) 2012 by the listed authors. All rights reserved. 
Colorado School of Mines

Division of Economics and Business

Working Paper No. 2012-07

August 2012

Title:

Renewable Electricity Policies,

Heterogeneity, and Cost Effectiveness*

Author(s):

Harrison Fell

Division of Economics and Business

Colorado School of Mines

Golden, CO 80401-1887

hfell@mines.edu

Joshua Linn

RFF (Resources for the Future)

linn@rff.org

\begin{abstract}
Renewable electricity policies promote investment in renewable electricity generators and have become increasingly common around the world. Because of intermittency and the composition of other generators in the power system, the value of certain renewables - particularly wind and solar-varies across locations and technologies. This paper investigates the implications of this heterogeneity for the cost effectiveness of renewable electricity prices as compared to one another and to a carbon dioxide emissions price. A simple model of the power system shows that renewable electricity policies cause different mixes of investment in renewable and other generator technologies. Policies also differ according to their effect on electricity prices, and both factors cause the cost effectiveness to vary across policies. We use a detailed, long-run planning model that accounts for intermittency on an hourly basis to compare the cost effectiveness for a range of policies and alternative parameter assumptions. The differences in cost effectiveness are economically significant, where broader policies, such as an emissions price, outperform renewable electricity policies.
\end{abstract}

JEL codes: L94, Q48, Q52 .

${ }^{*}$ We are grateful to the Heising-Simons foundation for supporting this research. 


\section{Introduction}

Numerous countries directly promote renewable generation technologies using a range of policies: renewable portfolio standards (RPSs), which mandate that a share of electricity generation come from renewable technologies; investment subsidies; production subsidies; and feed-in tariffs, which provide an above-market price of electricity for renewable generators. These policies, which we refer to as renewable electricity policies, create incentives for firms to invest in new renewable generator units. Their objective is to reduce carbon dioxide emissions $\left(\mathrm{CO}_{2}\right)$ by increasing the share of renewable generation in total generation. Whereas feed-in tariffs are common in Europe, RPSs and investment or production subsidies are far more common in the United States. In the U.S. electricity sector, the share of generation from renewable technologies (excluding hydroelectric) is expected to double between 2010 and 2030, from about 5 to 11 percent (Energy Information Administration (EIA) 2010). Tax credits and RPSs explain nearly all of this expected increase. Policies in Europe and elsewhere are expected to have similarly large effects.

The recent literature has begun to address how the cost effectiveness of renewable electricity policies compares to one another and to a $\mathrm{CO}_{2}$ emissions price. A first strand of the literature has investigated the market and environmental value of intermittent renewable generators — wind and solar in particular. Several studies have shown that the market value (market revenue minus costs) varies across renewable generators. The market value of a given generator depends on the correlation between the underlying resource availability and electricity prices or demand (Lamont 2008 and Joskow 2010). For example, wind is often (but not always) negatively correlated with electricity prices, and solar is usually positively correlated; the market value of a solar generator is often greater than that of a wind generator of equal cost.

The environmental value (avoided emissions) of generation from renewables depends on the type(s) of generation displaced, which in turn depends on the composition of generators in the system and the spatio-temporal availability of the renewable resources. Several recent studies have quantified this variation in environmental value. Cullen (2011), Castillo and Linn (2011), and Novan (2011) find considerable heterogeneity in the environmental value of wind generators in the Electricity Reliability Council of Texas (ERCOT) region. Kaffine et al. (2011) show that the environmental value of wind varies by a factor of two between California, ERCOT, and the upper Midwest; environmental value is greater in the coal-dominated Midwest than in natural gas-dominated California.

Thus, intermittency, electricity demand, and the composition of the generation stock cause variation in market and environmental value across intermittent renewable technologies. The literature suggests that if 
renewable electricity policies cause different mixes of renewables investment, cost effectiveness could vary across policies. These studies have not tried to quantify these differences, however.

The second strand of the literature uses economic models of the electricity sector to simulate alternative policy scenarios and compare their cost effectiveness. These studies - for example, Fischer and Newell (2008), Palmer et al. (2011), and Morris et al. (2010) — conclude that renewable electricity policies are more costly than an emissions price because they do not incentivize low-cost opportunities to reduce emissions such as using natural gas instead of coal to generate electricity. However, these models do not fully incorporate the potential heterogeneity across locations and renewable technologies because they have a fairly coarse treatment of intermittency; the studies typically aggregate demand and supply to 1020 time blocks.

This paper makes two contributions to the literature. We first use a simple model to provide intuition for why renewable electricity policies may have different cost effectiveness. The model shows that renewable electricity policies differ from one another because they (a) cause different investment in renewable generators and other generators; and (b) have different effects on electricity prices. We then compare policies by implementing a detailed simulation model that includes intermittency on an hourly time scale. Policies differ considerably in cost effectiveness, and the policies' effects on electricity prices explain most of these differences.

More specifically, Section 2 summarizes the main characteristics of renewable electricity policies, including RPSs, production subsidies, and feed-in tariffs. Typically, an RPS mandates a particular quantity of renewable electricity. An RPS implicitly subsidizes renewable generation, and therefore creates investment incentives similar to those created by a production subsidy. These policies tend to provide the same subsidy regardless of the environmental value - in effect, treating all renewable generation as equally environmentally valuable. A typical feed-in tariff goes even further, and by encouraging investment in the lowest-cost generators, it does not account for environmental value or market revenue of renewable generators. By comparison, under an emissions price, the revenue earned by a renewable generator depends on the market and environmental values.

To provide intuition for the simulation model, Section 3 uses a highly stylized electricity sector model to illustrate why cost effectiveness may vary across renewable electricity policies. The model shows that the cost effectiveness of policies varies because of heterogeneous market and environmental values and because of the effects on electricity prices, which we refer to as demand effects. The first strand of the literature has focused on incremental value, by which we mean the value arising from a small investment in wind or solar. Solar has higher incremental market value than wind because solar generation is more 
positively correlated with demand than is wind generation. ${ }^{2}$ Wind has higher environmental value than solar because it displaces more coal generation. In contrast, long-run value corresponds to the value arising from a significant amount of wind or solar investment, which affects investment in other technologies. The long-run environmental value of wind exceeds that of solar to the extent that wind investment displaces more coal investment.

We use the simple model to compare the policies' cost effectiveness-defined as the change in producer and consumer welfare divided by the change in emissions - relative to the no-policy case. The relative cost effectiveness of an RPS and feed-in tariff is uncertain: the feed-in tariff is more cost effective if lowcost generators (which receive the strongest investment incentives) have high environmental value and if demand effects are small. Otherwise, the RPS is more cost effective. With vertical demand curves, the RPS and production subsidy are identical, as are an emissions price and a clean electricity standard (which credits technologies based on their emissions rates). Downward-sloping demand curves cause the RPS to outperform the production subsidy and the emissions price to outperform the clean electricity standard. Thus, cost effectiveness depends on the mix of renewables and on demand effects.

Finally, we relax many of the assumptions in the simple model and use a highly detailed planning model to compare several hypothetical renewable electricity policies and an emissions price. As Section 4 describes, we model the ERCOT region and simulate investment in coal, natural gas, wind, and solar generation capacity. We focus on ERCOT because (a) Texas contains the most installed wind capacity of any state; (b) ERCOT oversees a wholesale electricity market and publishes a large amount of data; and (c) several features of the power system reduce modeling complexity. The model is similar to that of Bushnell (2010), although renewable investment is endogenous in our model. Gowrisankaran et al. (2011) use a similar type of model to study solar generators in Arizona. Our approach to studying renewable policies differs from that of many engineering studies of the integration of large amounts of renewable generators because such studies typically assume a particular level and type of investment (e.g., New York Independent System Operator 2010; and GE Energy 2010). In addition, our aims differ from other studies that identify optimal investment paths under environmental or other objectives; we use a similar modeling approach, but the objective is to understand the reasons why cost effectiveness differs across policies.

Because the simple model showed that differences across policies depend partly on environmental and market values of renewable generators, in Section 5 we use the model to compare incremental and long-

\footnotetext{
${ }^{2}$ The assumption that solar generation is more positively correlated with demand than is wind generation captures typical conditions in the United States.
} 
run values of wind and solar. Similarly to the previous literature, across technologies we find sizeable differences in incremental market value and much smaller differences in incremental environmental value. The long-run environmental value of wind is greater than the incremental value because the long run includes the benefits of displaced investment as well as displaced generation. However, long-run environmental value varies only slightly across different renewable generators, whether they are solar or various types of wind generators. The similarity arises largely from the fact that the technologies displace gas investment rather than coal investment.

In Section 6, we compare the cost effectiveness of different renewable electricity prices and a $\mathrm{CO}_{2}$ emissions price. We find that the RPS outperforms the feed-in tariff because a) the RPS encourages investment in generators with high market value, and differences in market value outweigh differences in environmental value; and b) the RPS causes higher electricity prices, which reduces consumption and associated emissions. The second reason also explains why the RPS outperforms the production subsidy. The clean electricity standard is less cost effective than the emissions price because it causes a smaller increase in electricity prices. However, the clean electricity standard is much more cost effective than the other renewable electricity prices because it encourages fuel switching in addition to investment in renewables. In short, we find that much of the difference across policies arises from demand effects, although heterogeneous market value helps explain why the RPS outperforms the feed-in tariff.

The importance of demand effects arises from recent decreases in natural gas prices and from greenhouse gas (GHG) regulations for new fossil fuel generators. Between 2008 and 2011, the 2030 forecast of the real retail natural gas price by the Department of Energy's Energy Information Administration has decreased by about 20 percent. Furthermore, recent GHG emission rate standards for new fossil fuel generators make coal investment unlikely until the expected cost of carbon capture and sequestration decreases substantially. ${ }^{3}$ These developments have caused most analysts to forecast zero investment in new coal generators over the next two decades, which our simulations confirm. The lack of coal investment causes the long-run environmental values of different technologies to be more similar than if there were coal investment in the no-policy scenario.

\section{Taxonomy of Renewable Electricity Policies}

This section describes the essential features of the policies analyzed in this paper: a price on $\mathrm{CO}_{2}$ emissions, a feed-in tariff, an RPS, a clean electricity standard, and a production subsidy.

\footnotetext{
${ }^{3}$ Other policies, such as California's prohibition against new long-term contracts with coal generators also reduce the likelihood of coal investment in the near future.
} 


\subsection{Carbon Dioxide Emissions Price}

We consider a stylized emissions price that raises the cost of generating electricity in proportion to the emissions rate of the technology. The emissions price raises the costs of each technology by a different amount. The emissions rate of a typical coal generator is about one ton of $\mathrm{CO}_{2}$ per megawatt-hour $(\mathrm{MWh})$, and an emissions price of $\$ 30 /$ ton of $\mathrm{CO}_{2}$ would increase the marginal cost of such a coal generator by about $\$ 30 / \mathrm{MWh}$. Efficient natural gas units have a $\mathrm{CO}_{2}$ emissions rate about half that of coal. On the other hand, the emissions price does not affect the costs of renewable generators that produce zero emissions.

\subsection{Feed-in Tariffs}

In many markets, producers of renewable electricity receive a guaranteed price for each unit of electricity generation. These programs, often called feed-in tariffs, are much more common in Europe than in the United States. They can be financed in many ways, such as via a flat charge to ratepayers.

From the perspective of the owner of a renewable electricity generator, the feed-in tariff affects both the total revenue received and uncertainty over the revenue. Two primary dimensions define feed-in tariffs: whether the tariff is offered in place of the market price, and whether it varies over time. Each of the four combinations is feasible. In Germany, for example, owners of certain generation technologies receive a fixed price regardless of when the electricity is produced, and this price is received instead of the market price of electricity. Alternatively, the owner of the generator could receive a prespecified price from the electric utility in addition to the price received in a wholesale market. If the market price is uncertain and generator owners are risk averse, the value of this arrangement would be lower than a price guarantee of equal expected value that replaces the market price. However, in this paper we abstract from uncertainty, and this distinction does not matter for our analysis. Therefore, we assume that the feed-in tariff is offered in place of the market price.

For two reasons, this paper considers a time-invariant feed-in tariff that replaces the market price. First, a time-invariant total price is the scheme Germany has used, which is perhaps the most prominent example of a feed-in tariff system. Second, if the tariff is offered above the market price, and it does not vary over time, it is equivalent to an RPS, which is discussed next. ${ }^{4}$

\footnotetext{
${ }^{4}$ Another type of policy might offer a time-of-use feed-in tariff, for example differentiating between seasons of the year (summer vs. nonsummer) and time of day (daytime peak vs. nighttime off-peak). To keep the number of cases manageable, we do not consider this possibility.
} 


\subsection{Renewable Portfolio Standards and Clean Electricity Standards}

About 30 states currently have RPS programs, which specify that a certain fraction of electricity must come from renewable electricity technologies. Wind, solar, biomass, geothermal, and other technologies typically qualify as renewable, with some states allowing existing hydroelectric to qualify. ${ }^{5}$

States implement the mandate in a variety of ways, but the most common approach is to establish a renewable energy certificate (REC) system. A qualifying renewable generator creates a REC for each MWh of electricity it generates. The RPS requires that each electricity retailer purchase RECs in proportion to its electricity sales. For example, with a 20 percent RPS, a retailer that sells 100,000 MWh of electricity must purchase 20,000 RECs. Retailers can purchase RECs from a renewable generator at the same time that they purchase electricity from that generator, or they can purchase from another entity such as a utility that exceeds the standard and has excess RECs to sell. This system establishes a market for RECs in which the price of a REC is in units of dollars per MWh.

For a renewable generator, the REC system creates additional revenue. For example, if the REC price is $\$ 20 / \mathrm{MWh}$, the owner of the renewable generator receives $\$ 20$ for each MWh it produces. This revenue is earned in addition to revenue from the electricity market. Therefore, putting aside REC price uncertainty, from the perspective of a renewable generator owner, an RPS is equivalent to a flat subsidy above the market price.

A clean electricity standard is related to an RPS. Such standards have been proposed lately, in which technologies receive credits in accordance with their emissions rates relative to that of a coal generator. For example, in a recent U.S. Senate proposal, wind, solar, and other renewables receive one credit per MWh of generation, and natural gas receives about one half credit because the emissions rate of natural gas is about half that of coal. The target is defined similarly to the RPS, counting renewables fully and counting a fraction of natural gas towards the target.

\subsection{Production Subsidy}

A production subsidy offers a prespecified subsidy for each unit of electricity generation. In principle, the subsidy could vary over time or depend on other factors such as geography, but in practice the subsidy tends to be offered as a fixed amount. In the United States, the most important production subsidy is the tax credit of about $\$ 22 / \mathrm{MWh}$ for wind generators and certain other technologies, which is indexed to inflation.

\footnotetext{
${ }^{5}$ A few states implement their RPSs as capacity requirements. Some states allow for a broader range of technologies to qualify, including nuclear generation.
} 
It is possible to subsidize investment instead of production. For example, the United States offers a tax credit of 30 percent of the upfront investment cost, which owners of many solar generators and other technologies have claimed. In this paper's analysis, in which there is no uncertainty about a generator's production, future fuel prices, and demand, and in which there is no ability to substitute between capital and other inputs, an investment and production subsidy can be designed to result in the same equilibrium. However, under many alternative assumptions a production subsidy is likely to be more cost effective.

\subsection{Summary of the Policies}

An emissions price reduces the relative cost of renewable technologies by raising the costs of fossil fuelusing technologies. The other policies implicitly or explicitly subsidize renewable generators. The feed-in tariff fixes the price for each unit of electricity generation, whereas the RPS effectively raises the price above the market price by a fixed amount, which is the same as a production subsidy. However, the RPS differs from the production subsidy in that the implicit subsidy is endogenously determined in the REC market, whereas the regulator sets the production subsidy.

\section{Simple Investment Model}

This section describes a very simple model of an electricity market in which firms invest in generation capacity and generators produce electricity to meet demand. The model includes two types of renewable generators. We compare the environmental and market values of the renewable generators and compare the cost effectiveness of renewable electricity policies.

\subsection{Model Structure and Equilibrium}

\subsubsection{Structure of the Electricity Market Model}

The market has three time periods: $t=0,1,2$. Period 0 is the investment stage, in which firms decide whether to construct generation capacity of different technologies. Electricity markets are present in periods 1 and 2. Demand is perfectly inelastic, and $D_{1}$ and $D_{2}$ denote the MWh of electricity demand in the two periods, where $D_{2}>D_{1}{ }^{6}$

The four generation technologies include coal (c), natural gas (n), wind (w), and solar (s). There is free entry in period 0 , with an infinite number of ex ante identical potential entering firms. Therefore, firms enter until profits equal zero. A firm chooses a technology and is able to invest in $1 \mathrm{MW}$ of generation

\footnotetext{
${ }^{6}$ Given the importance of price effects in the detailed simulation model, the assumption of inelastic demand curves may seem to be restrictive. However, the magnitude of the price changes in the simple model provides insight into how the policies differ from one another in a model with downward-sloping demand curves.
} 
capacity of that technology. The cost of capacity for technology $i$ is $K_{i}$, and these costs are completely sunk in period 0 . The capital cost for coal is greater than that for natural gas: $K_{c}>K_{n}$. Coal and natural gas firms decide whether and how much electricity to produce in periods 1 and 2, where the marginal costs are $0<m_{c}<m_{n}$. The fixed and marginal costs of coal and natural gas are such that if both technologies produce at full capacity in periods 1 and 2, the average cost of coal is lower than that of natural gas: $\frac{K_{c}}{2}+m_{c}<\frac{K_{n}}{2}+m_{n}$. However, if each technology produces in only one period, the average cost of natural gas is lower.

Wind generators produce electricity in period 1 but not in period 2, and solar generators produce electricity in period 2 but not in period 1; wind is negatively correlated with demand, and solar is positively correlated. We refer to these technologies as wind and solar for convenience, but the technologies could also represent wind locations that differ as to the correlation between wind resource availability and electricity demand.

The marginal generation cost is zero for wind and solar. For the first unit of wind capacity, the capital cost is $\bar{K}_{w} / \alpha$, where $\alpha$ is a positive constant. However, capital costs increase with additional entry, such that if $N_{w}$ is the total wind capacity, the capital cost of the marginal entrant is $K_{w}\left(N_{w}\right)=\bar{K}_{w}\left(1+N_{w}\right) / \alpha$ so that $K_{w}^{\prime}>0 .{ }^{7}$ Similar conditions hold for solar.

In periods 1 and 2, a firm operates its generator as long as the price exceeds the marginal cost. Because marginal costs do not vary with generation, when the price exceeds the marginal cost, the firm operates its generator at full capacity. In the investment phase in period 0 , a firm invests in new generation capacity based on the prices in periods 1 and 2; there is no uncertainty in the model. Let $N_{i}$ be the total amount of generation capacity of technology $i$ installed in period 0 . The $\mathrm{CO}_{2}$ emissions rates (tons per $\mathrm{MWh}$ ) of the technologies are given by $e_{c}>e_{n}>e_{w}=e_{s}=0$.

Before discussing the equilibrium in detail, it is useful to consider the implications of the cost assumptions. First, because capital costs are positive, if there is positive investment in any particular technology, the electricity price must exceed the marginal cost of that technology in at least one period. Second, because the model includes free entry and coal has higher fixed costs and lower marginal costs than natural gas does, if there is investment in both coal and natural gas, it must be the case that coal operates in both periods and natural gas operates in period 2. Third, because capital costs for wind and

\footnotetext{
${ }^{7}$ Alternatively, the model could include variation across locations in the capacity factor of the renewable generator. This approach would yield similar conclusions.
} 
solar increase with investment, there is a cutoff level of entry such that the last entrant for either technology earns zero profits.

\subsubsection{Unregulated Market Equilibrium}

Equilibrium is characterized by market prices and quantities for periods 1 and 2, and period 0 investment for each technology, $N_{i}$. The equilibrium values can be determined from (a) the free entry conditions for each technology (whereby profits for identical entering firms equal zero) and (b) market equilibriums in periods 1 and 2 .

To illustrate the differences among the policies, we assume that capital costs of wind and solar are sufficiently high that, without any environmental regulation (an emissions price or renewable electricity policy), there is no investment in either renewable technology. Furthermore, coal operates in both periods, and natural gas operates in period 2. Therefore, investments in coal and natural gas are given by $N_{c}^{*}=D_{1}$ and $N_{n}^{*}=D_{2}-D_{1}$. Free entry conditions determine the market prices: $p_{2}^{*}=K_{n}+m_{n}$ and $p_{1}^{*}=K_{c}+$ $2 m_{c}-K_{n}-m_{n}$. Figure 1 illustrates the market equilibrium for periods 1 and 2 .

Note that the price in period 2 exceeds the marginal costs of natural gas generators. The difference between price and marginal cost reflects the value of the capacity - that is, the value of having an additional unit of capacity that able to produce electricity if one of the other generator experiences an unexpected outage (such outages are not included in the model; this example is for heuristic purposes). ${ }^{8}$ Alternatively, to reflect the regulatory environment in much of the country, we could introduce to the model price caps and a separate capacity market. However, the main conclusions would be the same in such a model, at the cost of additional modeling complexity. ${ }^{9}$

Total emissions include the emissions from coal in period 1 and from coal and natural gas in period 2. Emissions equal $E^{*}=2 D_{1} e_{c}+\left(D_{2}-D_{1}\right) e_{n}$. The total cost of supplying electricity is equal to $C^{*}=$ $D_{1}\left(K_{c}+2 m_{c}\right)+D_{2}\left(K_{n}+m_{n}\right)$.

\subsection{Incremental Environmental and Market Values}

We define the incremental market value of a renewable generator as the difference between revenue and costs for a single renewable generator. Incremental environmental value is defined as the avoided $\mathrm{CO}_{2}$ emissions per MWh of renewable generation.

\footnotetext{
${ }^{8}$ The period 1 price also exceeds the marginal costs of the coal generators. The difference between price and marginal cost in period 1 arises because all coal generators have identical marginal costs, and likewise for natural gas, and because of the gap between the marginal costs of the coal and natural gas generators. If these assumptions were relaxed, the price would exceed marginal costs only in the high-demand period, i.e., period 2.

${ }^{9}$ Furthermore, there are currently no price caps or capacity markets in the ERCOT market, which is the focus of the analysis in Sections 5 and 6.
} 
Starting from the equilibrium described above, we consider the effects of adding an incremental amount of solar or wind generation capacity. First, suppose that a single unit of wind capacity were installed unexpectedly after coal and natural gas generators have committed to generating in period 1 - that is, assuming the same levels of coal and natural gas investment as in Figure 1. Wind displaces coal and receives a market price of $p_{1}^{*}$.

Alternatively, suppose that a unit of solar capacity is added unexpectedly after coal and natural gas generators have committed to generating in period 2. Solar displaces natural gas generation and receives a market price of $p_{2}^{*}>p_{1}^{*}$, which is higher than that of the wind generator. Solar receives a higher price because of the positive correlation between solar generation and demand and the differences in marginal costs across time periods.

The environmental value of the wind generation is proportional to the $\mathrm{CO}_{2}$ emissions rate of a coal generator. Similarly, the environmental value of the solar generation is proportional to the $\mathrm{CO}_{2}$ emissions rate of a natural gas generator. The differences in environmental value arise from the correlation between renewable generation and the probability that coal is the marginal generation technology.

\subsection{Long-run Environmental and Market Values}

Non-incremental wind and solar investment affect investment and generation of other technologies. To analyze these effects, we consider a scenario in which there is an exogenous amount of wind or solar investment prior to period 0 . We define long-run environmental and market values similarly to the incremental values. Long-run environmental value is the change in $\mathrm{CO}_{2}$ emissions per MWh of renewable generation. Long-run market value takes the difference between revenue and costs per MWh of renewable generation.

First, suppose an exogenous amount of wind capacity is mandated by the government, $N_{w}$. Because the wind generators produce electricity during period 1 only, the wind generation has the same effect on investment and operations as reducing $D_{1}$ but leaving $D_{2}$ unchanged. Investment in coal and natural gas capacity are given by $N_{c}=D_{1}-N_{w}$ and $N_{g}=D_{2}-D_{1}+N_{w}$. Coal and natural gas generation are equal to capacity, so that coal generation in both periods is $D_{1}-N_{w}$ and natural gas generation in period 2 is $D_{2}-D_{1}+N_{w}$.

Electricity prices are determined by the free entry conditions for coal and natural gas generation. Electricity prices are the same as in the unregulated equilibrium: $p_{2}=K_{n}+m_{n}$ and $p_{1}=K_{c}+2 m_{c}-$ $K_{n}-m_{n}$. Figure $2 \mathrm{a}$ shows the new equilibrium. Because prices are the same as the unregulated 
equilibrium, the market value of the wind generation is therefore lower because investment costs increase with capacity (i.e., $K_{w}^{\prime}\left(N_{w}\right)>0 \_$.

The long-run environmental value of the wind generation is greater than the incremental case. The wind generation displaces coal generation in period 1 , just as in the incremental case. The lower coal investment also means that there is more natural gas investment, so that in period 2, natural gas generation is higher and coal generation is lower than in the unregulated equilibrium. The environmental value of the wind generation is $2 e_{c}-e_{g}>e_{c}$.

To compare with the wind results, suppose instead that there is an exogenous amount of solar capacity installed prior to period $0, N_{s}$. Figure $2 \mathrm{~b}$ illustrates the new equilibrium. Because the solar generators produce electricity in period 2 but not in period 1, coal investment is unaffected. Natural gas investment is $N_{g}=D_{2}-D_{1}-N_{s}$. As in the wind case, free entry conditions determine electricity prices, which are therefore the same as in the unregulated equilibrium. Solar displaces natural gas investment and generation but does not affect coal investment and generation.

Thus, the long-run environmental value of wind is different from the incremental environmental value, but for solar, the long-run and incremental environmental values are the same. The differing results for wind and solar suggest that because of intermittency, incremental environmental value is an imperfect predictor of long-run environmental value. Furthermore, the share of gas and coal in total investment causes the long-run cost effectiveness to differ between wind and solar; the differences would be eliminated if there were no coal investment in the unregulated equilibrium.

We also find that the long-run market values are lower than the incremental market values. This result would be strengthened if we allow for heterogeneous marginal costs across coal and natural gas generators.

\subsection{Long-run Effects of a Carbon Dioxide Emissions Price}

We compare a $\mathrm{CO}_{2}$ emissions price with renewable electricity. We compare investment, generation, electricity prices, emissions, and cost effectiveness across polices, defining cost effectiveness as the change in producer and consumer surplus divided by emissions relative to the unregulated equilibrium.

In a more general model, an emissions price causes emissions to decrease by (a) fuel switching (for example, using more natural gas and less coal, without changing investment); (b) efficiency improvements at fossil fuel generators, which lowers the emissions rates; and (c) changes in the 
investment mix. Because we focus on the last effect, we assume that parameter values are such that fuel switching does not occur, and we assume that efficiency improvements are not possible.

$\mathrm{A} \mathrm{CO}_{2}$ emissions price of $\tau$ is introduced prior to period 0 . The emissions price raises the marginal cost of coal generators by $\tau e_{c}$. The marginal cost of natural gas generators increases by $\tau e_{n}$, which is less than the increase for coal because natural gas has a lower emissions rate. The emissions price is small enough that the total marginal cost (including the cost of emissions) for coal remains less than that of natural gas: $m_{c}+\tau e_{c}<m_{n}+\tau e_{n}$. Consequently, no fuel switching occurs. The marginal costs for wind and solar do not change because they have zero emissions.

To sharpen the comparison with renewable electricity prices, suppose that the emissions price causes wind investment but no solar investment; coal operates in periods 1 and 2; and natural gas operates only in period 2.

As before, the free entry conditions for coal and natural gas determine the electricity prices for the two periods. The prices are

$p_{2}^{e p}=K_{n}+m_{n}+\tau e_{n}$ and

$p_{1}^{e p}=K_{c}+2 m_{c}+2 \tau e_{c}-K_{n}-m_{n}-\tau e_{n}$.

The price in period 2 increases in proportion to the natural gas emissions rate so that natural gas generators are compensated for the increase in generation costs. The price in period 1 increases by more than the emissions price multiplied by the emissions rate of coal because coal generators are less profitable in period 2 than they were without the emissions price, so the price must rise enough so that the coal firms earn zero profits. Thus, if $\tau$ is sufficiently low and $e_{c}$ and $e_{n}$ are sufficiently close, $P_{2}^{e p}>P_{1}^{e p}$. Furthermore, as long as $K_{S}(0)>p_{2}^{e p}$, no investment in solar occurs.

The free entry condition for wind determines the amount of wind capacity, $N_{w}^{e p}$. The marginal entering wind firm earns zero profits, so

$N_{w}^{e p}=\alpha\left(K_{n}+m_{n}+\tau e_{n}\right) / K_{w}-1$.

Assuming that the parameter values are such that this expression is less than $D_{1}$, the equilibrium coal investment is equal to $N_{c}^{e p}=D_{1}-N_{w}^{e p}$. Equilibrium natural gas investment is $N_{n}^{e p}=D_{2}-D_{1}+N_{w}^{e p}$.

Figure 3 shows the equilibrium in periods 1 and 2 . The period 1 price increases more than the period 2 price compared to the market equilibrium in Figure 1. 


\subsection{Renewable Electricity Policies}

This section discusses a feed-in tariff, an RPS, a clean electricity standard, and a production subsidy. Each policy is compared with the emissions price.

\section{Feed-in Tariff}

A feed-in tariff offers the same predetermined electricity price to wind and solar. Consequently, firms construct the lowest-cost renewable generators, regardless of the market and environmental value of the generators. Electricity consumers pay the feed-in tariff directly to the wind or solar firm. Therefore, there are two electricity prices: the feed-in tariff and the market price for natural gas and coal.

Maintaining the assumption that the wind capital cost is lower than the solar capital cost, we set the feedin tariff so that it causes the same investment as the emissions price. Therefore, the feed-in tariff must equal the period 1 electricity price for the emissions price: $F I T=K_{c}+2 m_{c}+2 \tau e_{c}-K_{n}-m_{n}-\tau e_{n}$.

The cost effectiveness of the feed-in tariff is the same as that of the emissions price. The electricity prices will be different from the emissions price equilibrium, however, because with the feed-in tariff, the prices received by the natural gas and coal generators in periods 1 and 2 are equal to the unregulated prices. The lower prices would reduce the cost effectiveness of the feed-in tariff relative to an emissions price if we relax the assumption that demand curves are vertical.

\section{Renewable Portfolio Standard}

The RPS requires $N_{r}^{R P S}$ MWh of renewable investment. We set the RPS so that it causes the same amount of renewable investment as the feed-in tariff.

Each MWh of renewable generation produces a REC that consumers must purchase. Given the REC price, the last entering renewable generator earns zero profits. ${ }^{10}$ The same REC price applies to wind and solar generators, and we assume that the REC is purchased during the period in which the renewable electricity is generated. Therefore, if the REC price is $P$ and the equilibrium electricity price in period 1 is $p_{1}$, wind generators receive $P+p_{1}$ in period 1 and nonrenewable generators receive $p_{1}$ for each MWh of electricity; analogous prices obtain for period 2 and for solar.

\footnotetext{
${ }^{10}$ Fischer and Newell (2010) show that an RPS implemented as a fractional requirement of renewable electricity effectively subsidizes renewable generation and taxes nonrenewable generation. Renewable generators are subsidized implicitly because they gain revenue by selling RECs, and nonrenewable generators are taxed implicitly because, from the perspective of the regulated entity (usually, the electricity retailer), purchasing a unit of nonrenewable electricity requires the additional purchase of a fraction of renewable energy. However, in the simple model here, electricity demand is price-inelastic, and the amount of renewable electricity is determined exogenously by the RPS. Consequently, the implicit tax does not affect the equilibrium quantities.
} 
Because renewable generators receive the same subsidy regardless of when the electricity is generated, firms invest in renewable generators that have the highest market value. For a given REC price, $P$, the RPS causes at least some solar investment if the capital cost is less than the electricity price received by solar: $K_{s}(0)<K_{n}+m_{n}+P$. Figure 4 shows the equilibrium with both wind and solar investment. The electricity price increases by the same amount in periods 1 and 2 . On the other hand, Figure 3 shows that, compared with the unregulated equilibrium, an emissions price raises $p_{1}$ more than $p_{2}$. Therefore, the RPS shifts investment from wind to solar as compared to the emissions price.

Whether the RPS or feed-in tariff is more cost effective depends on parameter values. In the cases considered here, the feed-in tariff causes the same investment and generation as the emissions price, and the RPS is inferior. For other parameter values, the reverse situation could occur. In general, the total cost of the RPS to producers and consumers is lower than that of the feed-in tariff because it encourages investment in the generators with the highest market value, as opposed to the lowest investment cost. On the other hand, the feed-in tariff may reduce emissions more - the feed-in tariff stimulates wind investment, which displaces coal; the RPS stimulates wind and solar, thereby displacing both coal and natural gas. Because the RPS is less costly but could reduce emissions by less, the cost effectiveness (cost per ton of emissions reductions) of the RPS could be higher or lower than that of the feed-in tariff.

\section{Clean Electricity Standards and Trading Ratios}

The RPS modeled above distinguishes between renewable and nonrenewable technologies. An alternative approach is to use trading ratios that depend on the technologies' emissions rates relative to coal's. By this approach, $1 \mathrm{MWh}$ of coal generation does not create any credits, $1 \mathrm{MWh}$ of natural gas generation creates $1-e_{n} / e_{c}$ credits, and $1 \mathrm{MWh}$ of renewable generation creates 1 credit. If the credit price is $P$, natural gas generators receive an implicit subsidy of $P\left(1-e_{n} / e_{c}\right)$ and renewable generators receive an implicit subsidy of $P$ compared to coal. By setting the credit price equal to the emissions price multiplied by the coal emissions rate $\left(P=\tau e_{c}\right)$, the clean electricity standard affects the relative profitability of the technologies by the same amount as the emissions price.

This property has two implications. First, a clean electricity standard accounts for heterogeneity in the market and environmental values of wind and solar generators. An RPS raises electricity prices by the same amount in periods 1 and 2, whereas the clean electricity standard raises electricity prices higher when coal is the marginal technology than when gas is. 
The second implication is that, for the same emissions reduction, a clean electricity standard has the same cost effectiveness as the emissions price. Note that this equivalence depends on (a) the homogeneity of coal and natural gas generators; and (b) perfectly price-inelastic demand curves.

\section{Production Subsidy}

As with the RPS, the production subsidy raises the value of each MWh of renewable electricity generation by the same amount. Because demand is perfectly price-inelastic, the equilibrium quantities are the same as for an RPS.

\subsection{Summary}

We derive four main conclusions:

1. Renewable electricity policies cause different mixes of investment and have different effects on electricity prices.

2. The relative cost effectiveness of an RPS and feed-in tariff is not clear. A feed-in tariff may be more cost effective under two conditions: (a) low-cost generators have high environmental value; and (b) differences in environmental value across renewable generators are large compared to differences in market value.

3. With vertical demand curves, a clean electricity standard causes the same investment as an emissions price and is more cost effective than the other policies.

4. If demand curves are vertical, an RPS is identical to a production subsidy; otherwise the RPS is more cost effective. Analogous conclusions obtain for an emissions price compared to a clean electricity standard.

\section{Data Sources and Planning Model}

We have assembled data for the ERCOT power system from a variety of sources. We use the data to implement the planning model in the next two sections.

\subsection{Wind and Solar Data}

The paper compares the cost effectiveness of different policies that promote wind and solar generation. Therefore we estimate the production characteristics of hypothetical wind and solar generators that would be constructed under different policies.

ERCOT has provided a data set of simulated hourly generation for hypothetical wind generators, which AWS TrueWind assembled from meteorological data. The sites were selected as part of an ERCOT 
transmission planning study, a goal of which was to identify the most promising wind sites in the region. Wind and atmospheric data were used to model the hourly production from existing and hypothetical wind farms. For each modeled wind unit, the data include hourly simulated generation from 2005 and 2006. There are 696 simulated units, each with a capacity of about $100 \mathrm{MW}$.

We introduce heterogeneity across generators by constructing two types of hypothetical wind generators. For each simulated wind generator, we compute the correlation between hourly generation and load for 2005 and 2006. We assign units to two groups based on whether they fall above or below the median correlation. The average hourly capacity factor of both groups is computed. We refer to the groups as the high- and low-correlation wind generators.

Because Texas has very few solar installations, we use simulated solar generation data from the National Renewable Energy Laboratory's System Advisor Model. For 17 cities in Texas, we estimate the hourly generation of a hypothetical 10-MW solar photovoltaic (PV) plant. The simulated generation corresponds to a typical year rather than a specific year, and the data are aggregated similarly to the wind data.

\subsection{Electricity Demand and Generator Data}

To match the wind and solar data, hourly wholesale price and demand data are used from ERCOT for 2008. We aggregate the demand data across zones within ERCOT.

The generator data used in the planning model include a list of units in operation in ERCOT in 2008 but exclude units that ERCOT has determined are unavailable to meet load. For each unit, we estimate a heat rate (fuel input per unit of electricity generation), nonfuel operations and maintenance costs, and the fraction of time that the unit is unavailable because of scheduled maintenance or forced outages. We estimate the heat rate for large steam coal and natural gas generators from EIA Form 767, which account for almost 60 percent of the fossil fuel capacity in the sample. The U.S. Environmental Protection Agency (EPA) Continuous Emissions Monitoring System provides data for an additional 40 percent of the fossil fuel capacity. For the few remaining generators, we impute heat rates using the unit's capacity, age, and fuel type. For nuclear units, we use the estimated heat rates in the EPA National Electric Energy Data System database.

The nonfuel operations and maintenance costs are obtained from the Federal Energy Regulatory Commission, EIA, and EPA. Forced outage and maintenance rates are obtained from the North American Electric Reliability Corporation (NERC). See Paul et al. (2009) for further details on these data.

The marginal cost of each generation unit is equal to the operations and maintenance costs plus the heat rate multiplied by the fuel cost, where the fuel cost is from the EIA National Energy Modeling System 
(NEMS 2010). NEMS provides estimated fixed and variable costs of new generation units for each fuel type.

We note that many of these cost estimates are engineering-based and were not derived from actual data. However, Section 4.6 assesses the performance of the model by comparing simulation results with actual data from 2008.

\subsection{Basic Model Specification}

To compare the effect of each of the above-mentioned policies on investment decisions, we numerically solve a long-run planning model. The model consists of an initial capacity investment stage and a production stage, in which we compute the equilibrium quantity and price for every hour of the given production year under an assumed level of installed capacity, operating costs, and downward-sloping demand curves. The results of this production year are extrapolated across a 23-year production horizon to approximate production over the span 2008-2030. ${ }^{11}$

Given our assumed downward-sloping hourly demand curves, solving for the optimal level of investment presents several challenges relative to standard perfectly inelastic demand curve assumptions. De Jonghe et al. (2011) describe several ways to solve for the optimal level of capital investment in long-term investment planning models that include short-term demand response, such as that considered here.

Following this lead, the optimal investment portfolio maximizes the welfare of market participants subject to capacity utilization constraints. More specifically, given a set of existing generators, the maximization problem over new capital investments can be written as

$$
\begin{aligned}
& \max _{K^{N}} \sum_{t=1}^{T} \beta^{t}\left(\sum_{h=1}^{H} \int_{0}^{Q_{h t^{*}}} P_{h t^{*}}(Q) d Q\right)-\sum_{t=1}^{T} \beta^{t}\left(\sum_{i=1}^{I^{E x}} F O M_{i} K_{i}^{E x}+\sum_{h=1}^{H} c_{i t^{*}}^{E x} q_{i h t^{*}}^{E x}\right) \\
& -\sum_{t=1}^{T} \beta^{t}\left(\sum_{i=1}^{I^{N}} F O M_{i}^{N} K_{i}^{N}+\sum_{h=1}^{H} c_{i t^{*}}^{N} q_{i h t^{*}}^{N}\right)-\sum_{i=1}^{I^{N}} F_{i}^{N} K_{i}^{N}
\end{aligned}
$$

subject to

$$
\sum_{i=1}^{I^{E x}} q_{i h t^{*}}^{E x}+\sum_{i=1}^{I^{N}} q_{i h t^{*}}^{N}=Q_{h t^{*}}, \forall h
$$

\footnotetext{
${ }^{11}$ Alternatively, we can explicitly solve hourly equilibrium prices and quantities for every hour from 2008 to 2030. Solving the model in this way is quite computationally burdensome. We have found that solving for hourly equilibriums in a given year and extrapolating those results over several years leads to quite similar investment, welfare, and emissions results relative to the model that solves equilibriums for every hour of every year.
} 


$$
\begin{gathered}
q_{i h t^{*}}^{j} \leq C F_{i h t^{*}}^{j} K_{i h t^{*}}^{j}, \forall i, h \text { with } j=(E x, N) \\
q_{i h t^{*}}^{j} \geq T D_{i h t^{*}}^{j} C F_{i h t^{*}}^{j} K_{i h t^{*}}^{j}, \forall i, h \text { with } j=(E x, N)
\end{gathered}
$$

where $\beta$ is the discount factor, $Q_{h t^{*}}$ is the equilibrium quantity demanded in hour $h$ of the given production year $t^{*}$, and $P_{h t^{*}}(Q)$ is the inverse demand function. $I^{E x}$ includes the set of generators that existed prior to 2008 and whose costs and operation characteristics were estimated as described above. $I^{N}$ includes the set of generators constructed in 2008; new generators that have the same technology also have the same costs and operating characteristics. $F O M_{i t}^{j}$ is the fixed annual operating and maintenance cost for generator $i(j$ $=E x, N) ; K_{i t}^{j}$ is the installed capacity (in MW) of generator $i ; c_{i t}^{j}$ is the constant marginal cost of operating; $q_{i h t}^{j}$ is the production (in MWh) from generator $i ; F_{i h t}^{N}$ is the per-unit cost (in dollars per MW) of installing new generation capacity for technology $i$; and $C F_{i h t}^{j}$ is the capacity utilization factor of generator $i$. Finally, $T D_{i h t}^{j}$ is the minimum run (or "turndown") restriction parameter for generator $i$.

The first term of equation (1) represents the discounted sum of the consumer surplus from consumption in all hours of the production year $t^{*}$, as represented by the area under each hour's demand curve. The second term in equation (1) represents total costs of existing generators, which includes annual fixed costs and variable operating costs. The third term represents annual fixed and variable operating costs of new generators, and the final term represents capital costs of new generators. Thus, the new and existing generators differ in two ways. First, the fixed costs have already been incurred for the existing generators. Second, for new generators, costs vary across, but not within, technology types, whereas for existing generators, costs vary both within and across technologies.

The first constraint of the maximization imposes the market-clearing condition that the quantity supplied in each hour must equal the quantity demanded. The second constraint states that production from any given generator in hour $h$ of year $t^{*}$ must be less than or equal to the installed capacity for that generator multiplied by an hour-specific capacity factor $C F_{i h t^{*}}^{j}$.

Note that although the model includes a highly refined time dimension of the wholesale electricity market and gives careful consideration to the characteristics of the existing generation stock, the model admittedly omits several features present in most electricity markets. First, the model does not include operational constraints and costs, such as production ramp-up constraints or start-up costs. Although it would be possible to introduce ramping constraints or startup costs, the simulated generation patterns suggest that introducing these factors would not greatly affect the equilibriums, but doing so would impose considerable computational burden. 
Second, the model does not include transmission congestion. The addition of transmission to a model with an hourly time resolution and such a large set of generators and technologies would incur significant computing costs. We interpret the model as capturing long-run system behavior, and, at least for the case of ERCOT, it is reasonable to assume that transmission congestion does not impose significant costs in the long run. The substantial transmission investment in response to recent congestion in west Texas supports this assumption.

\subsection{Modeling Assumptions}

\section{General Model}

Assumptions regarding functional forms and parameter values are needed to implement the model. For the demand curve, we assume a linear functional form of $Q_{h t^{*}}=a_{h t^{*}}-b_{t^{*}} P_{h t^{*}}$.

To solve for the parameters of this demand curve, we first impose a price elasticity. The elasticity is meant to capture long-run responses of quantity demanded to the marginal electricity price. The empirical literature on the price elasticity of electricity demand provides a wide variety of potential values. For instance, based on state-level panel data sets, both Paul et al. (2009) and Maddala et al. (1997) found price elasticity estimates near -0.2. Using household-level data sets, Barnes et al. (1981) finds an elasticity of 0.55 , and Reiss and White (2005) find average elasticity of -0.39. More recently, using household-level data, and based on the assumption of average price responsiveness, Alberini et al. (2011) and Fell et al. (2012) estimate even larger price elasticities of -0.74 and -0.98 , respectively. To be on the conservative end of the spectrum of estimates, we assume that the average price elasticity of demand across the hours in a year is -0.2 .

With hourly average system prices and quantities for ERCOT in 2008, we solve for the slope parameter $b_{1}$ that yields an average price elasticity of demand of -0.2. In doing so, we solve for the initial intercept values, $a_{h 1}$, in each hour $h$. Over the 23-year analysis, we assume an annual percentage growth rate of 0.2 percent for the intercepts, so that $a_{h t^{*}}=\left(1.002^{t^{*-1}}\right) a_{h 1}$. The growth rate is equal to the growth rate observed from 2003 to 2010 . The slope of the curve remains constant $\left(b_{t^{*}}=b_{1}\right)$.

On the supply side, we begin with the existing generators. As mentioned above, we have data from multiple sources on individual generators in ERCOT in 2008. Marginal costs, $c_{i t}^{E x}$, are estimated from the estimated heat rates, fuel costs, and variable operation and maintenance costs. Fixed operating and maintenance costs, $F O M_{i}^{E x}$, are taken directly from the data.

We estimate hourly capacity factors for each generator, $C F_{\text {int }}^{E X}$. This variable is formed from the NERC data on the shutdown rates (in percentage of total annual hours) for both scheduled maintenance and 
forced outages. For the existing generators besides wind or solar, we assume that the scheduled maintenance occurs in ERCOT's low-demand months: February-April and October-December. We reduce the $C F_{\text {int }}^{E X}$ of non-wind/non-solar existing generators by a constant rate over these months, such that the average capacity factor across all hours of the year for each generator matches its reported average rate. More specifically, if scheduled maintenance is to occur over $N_{d}$ days and the generator otherwise has a capacity factor of one, the capacity utilization factor over the $N_{d}$ scheduled maintenance days is $\left(\left(1-s_{i}\right) H-\left(H-24 N_{d}\right)\right) /\left(24 N_{d}\right)$, where $s_{i}$ is generator $i$ 's average annual hourly shutdown rate for scheduled maintenance and $H$ is the number of hours in the year $(8,760) .{ }^{12}$ For the closures due to unscheduled maintenance on the nonrenewable generators, we assume that in each hour of the year, including those in the assumed scheduled maintenance period, the capacity factor is lowered by a constant rate such that the cumulative reduction in the capacity factor is equal to the average unscheduled maintenance rate.

For the turndown restriction, we set $T D_{i h t}^{j}=0.4$ for existing and new coal generators. For combined cycle natural gas plants, we set $T D_{i h t}^{j}$ at a slightly lower rate of 0.3 . All other generators have no turndown restrictions (i.e. $T D_{i h t}^{j}=0$ ). These values are consistent with those used by the EIA in their modeling of the ERCOT region.

For newly installed capacity, $K^{N}$, we assume that one could invest in 5 possible technologies: coal with $\mathrm{NO}_{\mathrm{X}}$ and $\mathrm{SO}_{2}$ scrubbing, natural gas combined cycle, wind with high demand correlation, wind with low demand correlation, and solar. ${ }^{13}$ Capital costs and operation costs for these technologies are based on cost assumptions in the Annual Energy Outlook 2010 (EIA 2010). Table 1 summarizes these costs. For nonrenewable technologies, the capacity factors are formed in the same manner as for the existing generators, with the scheduled maintenance rate and the forced outage rate for each technology taken as the capacityweighted average of these rates across the existing generators with the corresponding technologies. We also assume that, regardless of the chosen level of investment, investment in each of the non-renewable technologies enters the system as individual plants. That is, we do not subdivide the chosen total level of investment in a specific non-renewable technology into multiple smaller units when solving the hourly market equilibriums.

\footnotetext{
${ }^{12}$ In reality, a generator would completely or nearly shut down for a shorter interval rather than at a constant rate over the assumed six-month scheduled maintenance period. Because we do not know the exact days of the generators' closures, we hope to mimic the aggregate behavior of the generators by reducing the capacity utilization by a constant amount over the assumed scheduled maintenance period.

${ }^{13}$ Originally, we also allowed for investment in nuclear, integrated coal-gasification combined cycle, and natural gas combustion turbine technologies. However, we found that, given the cost assumptions and policy scenarios, there was never investment in these technologies, so we dropped them from consideration.
} 
For wind technologies, we begin by assuming that the initial investment in wind receives the same capacity utilization factors as the existing wind generation. However, average capacity factors (which are inversely proportional to average costs) vary across wind generation units. We assume that the highest average capacity factor units of each type are built first, and we construct a wind "supply curve" based on the AWS TrueWind data. Then, for each $100 \mathrm{MW}$ of incremental wind investment chosen by the maximization routine, we scale down the hourly capacity factor so that the average capacity factor for each increment is approximately equal to the average in the simulated wind supply curve. Thus, each increment of new wind generation has a slightly lower average capacity factor than the previous increment. $^{14}$

As mentioned above, the hourly capacity factor values for solar are based on estimates by the National Renewable Energy Laboratory's System Advisor Model of hourly generation for a hypothetical 10-MW solar PV plant. We assume that the average capacity factor for each new $100 \mathrm{MW}$ of solar capacity installed decreases with cumulative investment at the same rate as that of wind. That is, we use the same supply curve for solar as we do for wind. Such a supply curve may be overly pessimistic for solar, but using flatter supply curves does not affect the main conclusions.

We generate measures of producer and consumer welfare as given in equation (1). To generate a welfare measure for a given level of existing and newly installed capital, we first solve for the equilibrium quantity and price in each hour over the production year examined, which was year 2018 in all modeled scenarios. We do this by generating the supply curve, which is the summation of ordered marginal cost curves for the total available production in each hour. This ordering also effectively sets the dispatch order for the generators. At price points where existing capital and newly installed capital have the same variable operating costs, we assign a dispatch order such that production from existing capital is used first. ${ }^{15}$ We then find the equilibrium quantity and price as the intersection of the hour-specific supply and demand curves. Given the equilibrium price and quantity each hour, along with the assumed demand functions and marginal cost curves, we can calculate an hourly social welfare measure. Assuming every hour of the day for all years in our planning horizon has the same hourly social welfare as those determined for our representative production year, our total social welfare is the discounted value of these measures less the cost of new capital investments.

\footnotetext{
${ }^{14} \mathrm{We}$ assume that any chosen investment level is broken down into $100 \mathrm{MW}$ wind farm blocks and that any remaining generation enters as a wind farm with less than $100 \mathrm{MW}$ capacity. For instance, if the model solves for a wind investment level of 3,550 MW, this enters as thirty-five $100 \mathrm{MW}$ wind farms and one $50 \mathrm{MW}$ wind farm, with the $50 \mathrm{MW}$ farm being built last and thus having the lowest average capacity factor.

${ }^{15}$ The dispatch order of the existing generators that have the same variable operating costs was randomly assigned before the maximization and is held constant over all time periods and over all policy iterations.
} 


\section{Policy Assumptions}

We consider a general RPS that credits all new wind and solar generation, as well as specific RPS policies that credit high-correlation wind, low-correlation wind, or solar. For each RPS, we assume existing renewable generators are exempt from the regulation (existing wind generators neither generate RECs nor need to comply with RPS standards). For the general RPS, the standard is met by imposing the following additional constraint on the model:

$$
R P S_{g}=\frac{\text { Wind }+ \text { Solar }}{(\text { Wind }+ \text { Solar }+ \text { Coal }+ \text { Nat.Gas }+ \text { Nuclear })}
$$

where $R P S_{g}$ is the general RPS level, and Wind and Solar are the cumulative MWh of generation over the compliance period from new investment in wind and solar sources. ${ }^{16}$ Coal, Nat. Gas, and Nuclear are cumulative annual MWh of electricity generation from all (i.e., both existing and new) coal, natural gas, and nuclear generators. Similarly, for the renewable-specific policies, we impose the following constraint:

$$
R P S_{i}=\frac{\text { Renew }_{i}}{(\text { Wind }+ \text { Solar }+ \text { Coal }+ \text { Nat.Gas }+ \text { Nuclear })}
$$

where $R P S_{i}$ is the standard level for renewable-specific policy and Renew $w_{i}$ is the cumulative generation from new investment in renewable source $i$ over the compliance period with $i=$ high-correlation wind, low-correlation wind, or solar. ${ }^{17}$

As mentioned above, the RPS is typically operationalized via the creation of RECs. A qualifying technology (e.g., a solar generator) creates a REC with each MWh of its production, and excess RECs can be sold to other regulated generators. Thus a non-qualifying technology experiences an increase in its marginal costs equal to $R P S_{i} \times P_{i}^{R E C}$, where $P_{i}^{R E C}$ is the price of the REC. A qualifying technology, $i$, receives an increase in its output price equal to $\left(1-R P S_{i}\right) \times P_{i}^{R E C} \cdot{ }^{18}$ To solve for the REC price, we assume that $P_{i}^{R E C}$ is such that the total profits of the last $100 \mathrm{MW}$ renewable capacity installed equals zero. That is, we assume that the REC price is just enough to subsidize new investment in renewables to meet the RPS standard.

\footnotetext{
${ }^{16}$ In all of our models the compliance period is one year. In reality, with credit banking and borrowing, compliance periods may stretch over several periods.

17 This formulation of the RPS implies that the new non-renewables generators must also submit permits equal to the RPS multiplied by the cumulative production over the compliance period.

${ }^{18}$ Unlike the RPS described in section 2.3 and RPSs generally used in practice, this formulation implies that renewable generators must comply with the RPS by forfeiting a portion of the RECs they create. We make renewables subject to RPS compliance because it greatly simplifies the determination of the hourly market equilibrium conditions in the numerical model. Note also that for the numeric long-run planning model, we make renewables subject to compliance in CES policies.
} 
Similar to the RPS, the clean electricity standard credits new renewable and natural gas generators, but natural gas generators only receive partial credit. More specifically, for the clean electricity standard, we introduce the following constraint:

$$
C E S=\frac{\text { Wind }+ \text { Solar }+0.5 N G_{\text {new }}}{(\text { Wind }+ \text { Solar }+ \text { Coal }+ \text { Nat.Gas }+ \text { Nuclear })}
$$

where $C E S$ is the standard level and $N G_{n e w}$ is the cumulative MWh of generation over the compliance period from new investment in natural gas capacity. The policy is operationalized via clean electricity credits (CECs). Given the form of (4), we assume each MWh of generation from new natural gas facilities generates 0.5 credits, whereas new wind and solar generation receives a full credit for each MWh of production. Thus, for non-credit-generating technologies, marginal costs increase by $C E S \times P^{C E C}$, whereas marginal costs fall by $(0.5-C E S) \times P^{C E C}$ for new natural gas generators and $(1-C E S) \times$ $P^{C E C}$ for new renewable generators. Again, to solve for $P^{C E C}$, we also impose a zero profit condition for the last $100 \mathrm{MW}$ of renewable capacity installed and for new natural gas capacity. ${ }^{19}$

For the emissions price policy, we set an emissions price, $P_{e}$ (in dollars per ton of $\mathrm{CO}_{2}$ emissions), equal to a constant value in all hours. Burning coal produces emissions at a rate of 0.1 tons of $\mathrm{CO}_{2}$ per mmBtu of heat input. Burning natural gas produces emissions at a rate of 0.05 tons of $\mathrm{CO}_{2}$ per $\mathrm{mmBtu}$ of heat input. Given a generator's heat rate (mmBtu per MWh), the emissions price increases marginal costs by $P_{e} \times($ emissions rate/heat rate). Because the revenue raised by this emissions price is returned to the consumers in a lump sum transfer, annual consumer surplus increases by total emissions multiplied by the value of the emissions price. $^{20}$

To approximate the federal production tax credit (PTC), we assume that renewable generators receive a subsidy per MWh of electricity generation in addition to the electricity price. To determine the level of this subsidy, we impose a zero profit condition for new renewable generation capacity. Because the PTC is financed by a lump sum transfer from consumers, annual consumer surplus decreases by the subsidy level multiplied by the cumulative generation from renewable sources. The level of the feed-in tariff is determined analogously and is financed similarly to the PTC.

\footnotetext{
${ }^{19}$ We assume that all new capacity of natural gas is identical in terms of cost and generation capabilities. It can thus be thought of as a single plant. We therefore impose the zero profit restriction for the total of new natural gas capacity installed, rather than breaking it up into subunits.

${ }^{20}$ We assume that the lump-sum rebate does not affect electricity consumption; i.e., the elasticity of electricity consumption to income is zero for the range of rebates considered in the policy scenarios.
} 


\subsection{Model Validation}

Supporting the validity of the generation portion of the planning model, Table 2 compares observed outcomes in ERCOT for 2008 with outcomes if we simulate our model for the year 2008 and constrain investment for each technology to equal zero. ERCOT data are taken from ERCOT's published price data for 2008, from the 2008 annual report (ERCOT 2008), and from the EPA Continuous Emissions Monitoring System. The table shows that the mean simulated price is nearly identical to the actual price. The other parts of the distribution agree fairly closely, although we tend to underestimate high prices.

The underestimation is perhaps not surprising given that we do not model a transmission network. However, the bottom of the table shows that the simulated generation shares and emissions are very close to the actual. The wind generation share is somewhat higher in the simulations, which is probably because of the $3 \mathrm{GW}$ of wind investment in 2008. The simulations are based on installed capacity at the end of 2008, whereas the actual data reflect the fact that many of the wind generators did not come online until the end of the year. The coal and nuclear shares in the simulations are very similar to the actual data. The natural gas share is lower in the simulations, which is at least partly explained by the difference in wind generation shares. Total $\mathrm{CO}_{2}$ emissions from the simulation are 172.45 million tons, while actual $\mathrm{CO}_{2}$ emissions are 187.06 million tons. This difference is most likely explained by the additional wind generation included in our simulation.

\section{Incremental and Long-run Market and Environmental Values}

We use the planning model to compare the incremental and long-run market and environmental values of wind and solar generators. The incremental analysis reproduces results from recent research, and we compare these values with the long-run estimates that account for changes in investment and operation of other generators caused by investment in the renewables.

\subsection{Incremental Market and Environmental Values}

We use the simulation model to estimate the incremental market and environmental values of wind and solar generators. Market value is defined as the difference between the generation-weighted average electricity price and the average cost of producing electricity over the 23 -year period - that is, the profits of an incremental investment in a new generator, per MWh of generation. Environmental value is the avoided $\mathrm{CO}_{2}$ emissions per MWh.

The estimates are obtained by simulating the market equilibrium without any environmental policies. We use the hourly capacity factor for each of the three technologies (high-correlation wind, low-correlation wind, and solar) and the hourly electricity price to calculate the generation-weighted average hourly 
revenue in dollars per MWh. We calculate the average cost of the generator by taking the present discounted value of fixed and operating costs and dividing that by the present discounted value of generation over the 23-year period. We calculate the avoided emissions rate using the hourly capacity factor and the emissions rate of the marginal (highest cost) generator operating in the corresponding hour.

Table 3 reports the results. The average price for a high-correlation wind generator is about $\$ 2.43$ per MWh higher than that of a low-correlation wind generator. The difference, which is about 5 percent of the average price of a low-correlation generator, is consistent with the fact that a high-correlation wind generator is more positively correlated with demand (by construction) and therefore more positively correlated with electricity prices than is a low-correlation generator.

The third column in the table shows that the environmental value, as measured by the avoided emissions rate, is higher for a low-correlation wind generator than it is for a high-correlation wind generator. The difference is small in magnitude, however; $\mathrm{C} \mathrm{CO}_{2}$ emissions price of $\$ 30$ per ton implies a difference in environmental value of just $\$ 0.18$ per MWh. Thus, the difference in environmental value between the two types of wind generators is smaller than the difference in market value.

We define the incremental cost effectiveness as the market value divided by the environmental value. This measure corresponds to the change in producer and consumer surplus per avoided emissions caused by an RPS that mandates $1 \mathrm{MWh}$ of generation from the corresponding renewable technology. The final column reports that the cost effectiveness of the low-correlation wind generator is about $\$ 3$ per ton of $\mathrm{CO}_{2}$ better than for the high-emission generator.

Comparing the two types of wind generators with a solar generator, the average price for solar is higher because solar generation is more positively correlated with electricity demand - and therefore with the electricity price - than is wind generation. The lower price for wind generation is more than offset by the much higher average cost of generation for the solar generator, and the market value of the wind generator is higher than that of the solar generator.

On the other hand, the environmental value, in terms of avoided emissions per MWh of generation, is only slightly higher for wind than for solar. The difference arises from the fact that one MWh of wind generation displaces more coal generation than natural gas, although the difference is not large in absolute terms: given an emissions price of $\$ 30$ per ton $\mathrm{CO}_{2}$, the environmental value of a low-correlation wind generator is $\$ 0.51$ per MWh greater than that of a solar generator. The similarity in environmental value is consistent with the much lower cost effectiveness for solar than for wind, and it is also consistent with estimated incremental environmental value in Novan (2011). 


\subsection{Long-run Market and Environmental Values}

We estimate long-run values of the three renewable technologies - high-correlation wind, low-correlation wind, and solar-by imposing a technology-specific RPS that causes the corresponding technology to account for three percent of total generation. Before discussing the estimated long-run values, we report the investment in coal, natural gas, and the renewable technologies that occurs under each scenario. In Table 4, column 1 shows that, in the absence of any RPS, natural gas accounts for all of the new investment. This is because forecasts of natural gas prices are very low by historical standards; even a 20 percent increase in forecasted prices does not cause any investment in coal or other technologies.

The remaining columns show the investment by technology for each RPS. We observe that investment in natural gas capacity is very similar for the low- and high-correlation wind scenarios. However, natural gas investment is substantially lower for the solar scenario. This difference arises partly because solar displaces natural gas investment to a greater degree than does wind, which was illustrated in Section 3, and partly because solar has a higher average cost. Recall from Section 3 that electricity prices increase in proportion to the REC price. Because average costs for solar are so much higher than average costs for wind, and the average revenue for solar is only somewhat higher than for wind (see Table 3), the REC prices are much higher for the solar RPS than for the two wind cases; $\$ 206.06 / \mathrm{MWh}$ for solar and $\$ 62.53$ for high-correlation wind. The electricity price inclusive of the REC price is about 7 percent higher for the solar RPS, and, because demand curves are downward-sloping, electricity consumption is about 1.5 percent lower. ${ }^{21}$ In turn, the lower consumption causes less total investment. This effect was not present in the simple model because demand curves were assumed to be vertical, and it demonstrates the possibility that renewables policies can have different effects depending on how they affect electricity prices; we return to this issue in Section 6.

Table 5 reports the long-run market and environmental values of wind and solar generators, which are defined analogously to the incremental values. Market value is the difference between average price and average cost, where average price is the generation-weighted average price received by the new generators, and the average cost is the total cost (capital costs plus operations and maintenance) divided by the total discounted generation of the new generators. Environmental value is captured by the average avoided emissions rate, which is the change in emissions between the no-policy and RPS scenarios, divided by the incremental renewable generation. Multiplying the average avoided emissions rate by a

\footnotetext{
${ }^{21}$ Fischer (2010) demonstrates the possibility that an RPS can reduce electricity prices. In our simulations, this is not possible because we assume that the capital costs of incremental investment in coal or natural gas capacity are constant. This assumption is reasonable given the relatively small amounts of investment that occurs in the simulations. Each of the RPS scenarios increase electricity prices by a few percent on average compared to the nopolicy case.
} 
hypothetical $\mathrm{CO}_{2}$ emissions price yields the environmental value in dollars per $\mathrm{MWh}$, which can be compared to the market value. Long-run cost effectiveness takes the change in producer and consumer welfare and divides it by avoided emissions. Long-run cost effectiveness is directly comparable to its incremental counterpart.

Several results are apparent in Table 5. First, in the long run, the average price received by each renewable is lower and the average cost higher than they are in the incremental case. Long-run prices are lower because of the intermittency of wind and solar. Adding approximately $3 \mathrm{GW}$ of wind or solar reduces the amount of fossil fuel generation needed during hours when the renewable generation is relatively high, which decreases electricity prices in those hours. Long-run costs are higher than incremental costs because of the assumption that the capacity factor for each technology decreases with investment. We observe that long-run costs are only about 4 percent higher than incremental costs, which is because the wind data suggest that there are many high-quality wind locations in Texas and therefore capacity factors decrease gradually with total wind investment.

The second result is that although the avoided emissions per MWh of renewable generation are lower in the long run, the long-run cost effectiveness is substantially better for wind than is the incremental cost effectiveness. This is because the incremental cost effectiveness depends on the difference between the market value of the renewable generator and the marginal cost of the displaced fossil fuel generation. In the long run, however, the renewable generators displace some fossil fuel investment as well as fossil fuel generation. As a result, the long-run cost effectiveness is better than the incremental cost effectiveness. For solar, this effect is not as strong, although it is present.

The fact that there is only natural gas investment in the no-policy case has two implications for the longrun cost effectiveness of wind generation. The first is that the long-run cost effectiveness would be much better if there were coal investment (see Section 3). The second is that the long-run cost effectiveness is very similar for the high-correlation and low-correlation wind. Because it displaces more coal generation, the low-correlation wind is slightly more cost effective than the high-correlation wind; this effect would be even larger if the low-correlation wind displaced some coal investment as well. This result suggests that one of the implications of low natural gas prices is that long-run cost effectiveness of the wind technologies is very similar.

\section{$6 \quad$ Long-Run Cost Effectiveness of Alternative Policies}

We consider the five policies that were discussed in Sections 2 and 3: a $\mathrm{CO}_{2}$ emissions price, a clean electricity standard, an RPS, a production subsidy, and a feed-in tariff. We use the model in Section 4 to 
simulate each of these policies, where policies are calibrated to achieve an emissions reduction of 7.7 percent. We first compare the three renewables policies - the RPS, the production subsidy, and the feedin tariff - and then compare these policies with the broader policies - the $\mathrm{CO}_{2}$ emissions price and the clean electricity standard. For both sets of comparisons, we consider investment, generation, and cost effectiveness, which is defined as the welfare costs divided by the emissions reduction relative to the nopolicy scenario. Because emissions reductions are the same by construction, comparing cost effectiveness is equivalent to comparing welfare costs.

Table 6 reports the main summary statistics from these scenarios. The first column reports the no-policy case and the remaining columns report the five policy scenarios. Panel A reports investment by technology; Panel B reports generation and electricity prices in the middle year of the simulations, 2018; and Panel $\mathrm{C}$ reports total emissions, welfare, and cost effectiveness.

Column 1 repeats the results of the no-policy scenario from Table 4. Because projected natural gas prices are low compared to prices in the middle of the 2000s, natural gas accounts for all of the investment. Because of the low natural gas prices, equilibrium electricity prices are not sufficiently high for any wind investment to be profitable.

Columns 4-6 show the renewables policies. Column 4 introduces a 10 percent RPS that credits all renewables technologies equally (unlike the technology-specific policies from the previous section). The credit price is $\$ 70.12$ per MWh, which means that the renewables receive an implicit subsidy of $0.9 * \$ 70.12 / \mathrm{MWh}=\$ 63.11 / \mathrm{MWh}$. The RPS causes investment in the high- and low-correlation wind technologies, but there is more investment in the high-correlation wind technology. The difference is consistent with the simple model from Section 3. The RPS introduces an implicit subsidy that does not vary over time or across technologies. Therefore the RPS causes investment in the technology with the highest market value, which is the high-correlation wind. However, because the capacity factor of the marginal high-correlation wind generator decreases with cumulative investment in that technology, the cost of high-correlation wind investment increases with cumulative investment. As a result, some investment in the low-correlation wind is also profitable.

Column 5 shows that the production subsidy of $\$ 71.93$ per MWh causes a similar mix of wind investment as the RPS. However, there is more investment in the production subsidy scenario. As the model in Section 3 showed, although both the RPS and production subsidy subsidize renewables (either implicitly or explicitly), only the RPS taxes non-renewables (implicitly). Consequently, electricity prices are higher in the RPS, electricity consumption is lower, and hence there is less investment. As Panel C shows, this 
difference causes cost effectiveness (welfare loss divided by avoided emissions) to be about 50 percent worse for the production subsidy.

Column 6 shows that the feed-in tariff of $\$ 111.10$ per MWh causes an equal amount of investment in the high- and low-correlation wind technologies. ${ }^{22}$ This is consistent with Section 3, which showed that the feed-in tariff causes investment in the lowest-cost technology and does not take account of the value of the technologies. Because the costs of the two wind technologies depend on cumulative investment, and the costs are the same for the two technologies at the same level of cumulative investment, there is an equal amount of investment in the two technologies. Comparing columns 4 and 6, there are two important differences between the feed-in tariff and the RPS. First, the feed-in tariff causes more investment in the low-correlation wind than the RPS. Because low-correlation wind displaces more coal than highcorrelation wind, this effect causes more emissions reductions per unit of wind investment for the feed-in tariff than the RPS. On the other hand, the feed-in tariff causes lower electricity prices than the RPS, which tends to increase emissions per unit of wind investment. These effects therefore have opposing effects on overall cost effectiveness. The bottom of the table shows that the second effect dominates and that the RPS is more cost effective.

We turn to the broader policies, the $\mathrm{CO}_{2}$ emissions price and the clean electricity standard, which are reported in columns 2 and 3. An emissions price of $\$ 37.95$ per ton of $\mathrm{CO}_{2}$ reduces natural gas investment (compared to column 1) and causes no wind investment. Not surprisingly, the emissions price is much more cost effective than the renewables policies in columns 4-6. The latter policies reduce emissions primarily by causing more investment in renewables, whereas the emissions price encourages a broader range of emissions reductions opportunities. In particular, the emissions price causes switching from coal to natural gas generation and raises the price of electricity, which reduces consumption. Note that the RPS also puts upward pressure on electricity prices, but as Section 3 suggested and as Panel B in Table 6 shows, this effect is greater with the emissions price than with the RPS.

Column 3 reports the results for the clean electricity standard, in which the standard requires 15 percent of new clean electricity and the equilibrium credit price is $\$ 45.96$ per MWh. As the model in Section 3 illustrated, if demand curves are vertical, the clean electricity standard and emissions price cause the same equilibrium and have the same cost effectiveness. Therefore, differences between columns 2 and 3 in Table 6 arise because demand curves are not vertical in the simulation model. That is, the two policies differ because whereas the emissions price taxes generation in proportion to the emissions rate, the clean

\footnotetext{
${ }^{22}$ When comparing the incentives for new investment created by the renewables policies, recall that the renewable generators receive the feed-in tariff instead of the electricity price, whereas the production subsidy and RPS credit price are in addition to the electricity price.
} 
electricity standard imposes a smaller tax on dirty technologies and subsidizes clean technologies (where clean and dirty depend on the technology's emissions rate relative to coal and to the standard). The lower tax results in greater generation and lower electricity prices, as can be seen by comparing the results in columns 2 and 3 of Panel B. In fact, if we simulate the model assuming that the demand elasticity is approximately equal to zero, the CES and emissions price have nearly identical effects on investment, generation, electricity prices, and emissions.

To summarize the results from Table 6 and compare them with the predictions of the simple model in Section 3, we find that the RPS is more cost effective than the production subsidy because it causes higher prices and lower generation; hence, less wind investment is needed to meet a target emissions reduction. This result is consistent with the model in Section 3. That model also showed that it is generally ambiguous whether an RPS is more or less cost effective than a feed-in tariff-it depends on the market and environmental values of the different technologies. In the simulations considered here, the market value of the high-correlation technology is higher than the low-correlation, and the environmental values are about the same. Because the RPS favors the technology with high market value, it is more cost effective than the feed-in tariff in practice. The clean electricity standard is more cost effective than the RPS because it encourages fuel switching in addition to investment in renewables, which is also consistent with the model in Section 3. Finally, the emissions price is more cost effective than the clean electricity standard because it causes a greater reduction in generation and associated emissions.

We have performed some robustness analysis by simulating the model and policy scenarios under alternative assumptions (not reported, but available upon request). First, the equilibrium outcomes and relative cost effectiveness are very similar to those in Table 6 if we assume that natural gas prices will be 20 percent higher than current forecasts. The similarity suggests that very large increases in natural gas prices would be required for other technologies to be competitive with natural gas in the absence of a GHG policy. A further implication of the dominance of natural gas generation in total investment is that one of the results of the simple model - the possibility that long-run cost effectiveness varies across technologies - is not significant in the more detailed model. If policy or market conditions change and coal investment becomes more attractive, the long-run environmental value could vary more across technologies. This would increase the importance of intermittency in explaining differences in cost effectiveness across renewable electricity policies.

Second, in principle, at high levels of renewables penetration, turndown restrictions for fossil units could cause fuel switching from coal to gas because the coal units cannot operate at low levels of their rated capacity. By raising total generation costs, this could adversely affect the cost effectiveness of the 
renewables policies. To explore the implications of the turndown restrictions, we have simulated the model removing the restrictions. The results are qualitatively similar to those in Table 6 , suggesting that, in practice, the levels of renewables penetration considered here do not seem to be sufficient to create these effects. Finally, as noted above, the effects on equilibrium outcomes and cost effectiveness of the clean electricity standard and emissions price become more similar as the magnitude of the demand elasticity decreases towards zero.

\section{Conclusions}

This paper investigates the implications of hourly intermittency and demand effects for renewable electricity policies. We evaluate market and environmental values of renewable generators and compare incremental values with long-run values. Then we compare the cost effectiveness of alternative polices using a model that incorporates hourly generation of different technologies and the differing incentives for investment created by the policies.

We use a simple model of the electricity sector to demonstrate the different incentives for new investment created by renewable electricity policies. A feed-in tariff causes investment in the lowest-cost generators, regardless of their market or environmental value. An RPS and a production subsidy cause investment in generators with the greatest market value. A clean electricity standard causes investment in the generators with the greatest market and environmental value. Therefore, renewable electricity policies cause different mixes of investment in renewable and nonrenewable generation capacity.

Cost effectiveness may vary across policies because of heterogeneity across renewable generators and because of demand effects. The latter causes a clean electricity standard to be inferior to an emissions price and a production subsidy to be inferior to an RPS. Comparing an RPS and feed-in tariff, the RPS favors investment in generators with high market value, whereas the feed-in tariff favors low-cost generators. If low-cost generators also have high environmental value, the feed-in tariff could be more cost effective than the RPS.

We simulate generation and investment using a long-run planning model that incorporates heterogeneity across renewable generation units and includes details of other generation technologies in the power system. We find that different mixes of renewable and nonrenewable investment occur under the different policies. The results are consistent with the conclusions from the simple model. Because the clean electricity standard causes lower electricity prices than the emissions price, it is less cost effective. Similar differences arise between the RPS and production subsidy, and the differences are economically significant. In the simulations reported in this paper, the feed-in tariff is inferior to the RPS because 
differences in market value far exceed differences in environmental value. Finally, we note that recent decreases in natural gas prices and GHG emissions standards for new coal investment in the United States have decreased expected coal investment, thereby reducing heterogeneity in long-run environmental value and decreasing variation in cost effectiveness across policies.

Our model is deterministic. Some studies, such as Gowrisankaran et al. (2011), incorporate uncertainty in renewable generation. The general conclusion of this research is that the effects of this type of uncertainty are fairly small at low or moderate levels of penetration of wind or solar. However, the effects of other types of uncertainty, such as future fuel prices or environmental policies, remain open topics for future research.

\section{$8 \quad$ References}

1. Alberini, A., W. Gans, and D. Velez-Lopez. 2011. "Residential consumption of gas and electricity in the U.S.: The role of prices and income." Energy Economics 33, 870-881.

2. Barnes, R., R. Gillingham, and R. Hagemann. 1981. "The Short-run Residential Demand for Electricity." Review of Economics and Statistics, 1981, 63, 541-551.

3. Bushnell, J. 2010. "Building Blocks: Investment in Renewable and Non-Renewable Sources." Working Paper, University of California Energy Institute WP 202R.

4. Castillo, A., and J. Linn. 2011. "Incentives of Carbon Dioxide Regulation for Investment in LowCarbon Electricity Technologies in Texas." Energy Policy 39: 1831-1844.

5. Cullen, J. 2011. "Measuring the Environmental Benefits of Wind-Generated Electricity." Working Paper, Department of Economics, University of Arizona.

6. EIA (Energy Information Administration). 2010. Annual Energy Outlook 2010 with Projections to 2035. DOE/EIA-0383(2010). Washington, DC: EIA.

7. ERCOT. 2008. Electric Reliability Council of Texas 2008 Annual Report.

8. Fell, H., S. Li, and A. Paul. 2012. "A New Look at Residential Electricity Demand Using Household Expenditure Data." CSM Division of Economics and Business Working Paper 2012-04, Golden, CO.

9. Fischer, C. 2010. "When Do Renewable Portfolio Standards Lower Electricity Prices?" The Energy Journal 31(1): 101-120.

10. Fischer, C., and R. Newell. 2008. "Environmental and Technology Policies for Climate Mitigation." Journal of Environmental Economics and Management 55: 142-162.

11. GE Energy. 2010. Western Wind and Solar Integration Study. NREL/SR-550-47781. Golden, CO: National Renewable Energy Laboratory. 
12. Gowrisankaran, G., S. S. Reynolds, and M. Samano. 2011. "Intermittency and the Value of Renewable Energy." NBER working paper 17086. Cambridge, MA: National Bureau of Economic Research.

13. Joskow, P. 2010. "Comparing the Costs of Intermittent and Dispatchable Electricity Generation Technologies." MIT CEEPR working paper WP-2010-013. Cambridge, MA: Massachusetts Institute of Technology Center for Energy and Environmental Policy Research.

14. Kaffine, D. T., B. J. McBee, and J. Lieskovsky. 2011. "Emissions Savings from Wind Power Generation: Evidence from Texas, California, and the Upper Midwest." Working Paper, Colorado School of Mines.

15. Lamont, A.D. 2008. "Assessing the Long-Term System Value of Intermittent Electric Generation Technologies." Energy Economics 30: 1208-1231.

16. Maddala, G.S., R.P. Trost, H. Li, F. Joutz. 1997. "Estimation of Short-run and Long-run Elasticities of Energy Demand from Panel Data Using Shrinkage Estimators." Journal of Business \& Economic Statistics 15 (1), 90-100.

17. Morris, J.F., J.M. Reilly, and S. Paltsev. 2010. "Combining a Renewable Portfolio Standard with a Cap-and-Trade Policy: A General Equilibrium Analysis." MIT joint program report 187. Cambridge, MA: Massachusetts Institute of Technology.

18. New York Independent System Operator. 2010. "Growing Wind: Final Report of the NYISO 2010 Wind Generation Study.” Rensselaer, NY: New York Independent System Operator.

19. Novan, Kevin. 2011. "Valuing the Wind: Renewable Energy Policies and Air Pollution Avoided."

20. Palmer, K., A. Paul, and M. Woerman. 2011. "Federal Policies for Renewable Electricity." Discussion paper 10-53. Washington, DC: Resources for the Future.

21. Paul, A., D. Burtraw, and K. Palmer. 2009. "Haiku Documentation: RFF's Electricity Market Model Version 2.0." Washington, DC: Resources for the Future.

22. Paul, A., E.C. Myers, and K. Palmer. 2009. “A Partial Adjustment Model of US Electricity Demand by Region, Season, and Sector.” RFF Working Paper DP 08-50,Washington, DC.

23. Reiss, P. and M. White. 2005. "Household Electricity Demand, Revisited," Review of Economic Studies 72, 853-883. 
Tables:

Table 1

\begin{tabular}{|c|c|c|c|c|}
\hline \multicolumn{5}{|c|}{ Cost Assumptions } \\
\hline & Capital costs $(\$ / \mathrm{kW})$ & Heat rate (Btu/kWh) & $\underline{\text { Fixed O\&M }(\$ / \mathrm{kW})}$ & $\frac{\text { Variable O\&M }}{(\$ / M W h)}$ \\
\hline Coal & 2223 & 9200 & 28.15 & 4.69 \\
\hline Natural gas CC & 968 & 6752 & 11.96 & 2.04 \\
\hline Wind & 1966 & & 30.98 & 0.00 \\
\hline Solar & 3500 & & 11.94 & 0.00 \\
\hline
\end{tabular}

Notes : The table reports cost assumptions used in the simulations. All assumptions are from AEO 2010. 
Table 2

\begin{tabular}{|c|c|c|}
\hline \multicolumn{3}{|c|}{ Comparison of Simulation Model and Actual ERCOT Outcomes 2008} \\
\hline & $\underline{\text { Simulation model }}$ & $\underline{\text { ERCOT }}$ \\
\hline & \multicolumn{2}{|c|}{$\underline{\text { Panel A: electricity prices }}$} \\
\hline Average electricity price $(\$ / \mathrm{MWh})$ & 75.75 & 77.38 \\
\hline 10th percentile electricity price & 17.96 & 18.91 \\
\hline 25th percentile electricity price & 44.84 & 35.36 \\
\hline 75th percentile electricity price & 69.94 & 77.32 \\
\hline \multirow[t]{2}{*}{ 90th percentile electricity price } & 81.08 & 108.53 \\
\hline & \multicolumn{2}{|c|}{ Panel B: generation and emissions } \\
\hline Coal generation share & 0.40 & 0.39 \\
\hline Gas generation share & 0.37 & 0.41 \\
\hline Nuclear generation share & 0.14 & 0.13 \\
\hline Wind generation share & 0.08 & 0.05 \\
\hline $\mathrm{CO}_{2}$ emissions (million tons) & 172.45 & 187.06 \\
\hline
\end{tabular}

Notes : The first column reports statistics from a simulation of the planning model for the year 2008 that restricts investment for each technology to equal zero. The second column reports statistics from actual market outcomes in 2008. Prices in 2008 were obtained from the ERCOT website (www.ercot.com); coal generation share, gas generation share, and $\mathrm{CO}_{2}$ emissions are calculated from the EPA Continuous Emissions Monitoring System; and nuclear generation and wind generation are calculated from the ERCOT 2008 annual report (ERCOT 2008). The first row reports the generation-weighted average electricity price and the following rows report the indicated percentiles of the price distributions. 
Table 3

\begin{tabular}{lcccc}
\hline \multicolumn{4}{c}{ Incremental Market and Environmental Values } \\
\hline \hline & $\begin{array}{c}\text { Average price } \\
(\$ / \mathrm{MWh})\end{array}$ & $\begin{array}{c}\text { Average cost } \\
(\$ / \mathrm{MWh})\end{array}$ & $\begin{array}{c}\text { Avoided emissions } \\
\text { rate }\left(\text { tons } \mathrm{CO}_{2} / \mathrm{MWh}\right)\end{array}$ & $\begin{array}{c}\text { Cost effectiveness } \\
\left(\$ / \text { ton } \mathrm{CO}_{2}\right)\end{array}$ \\
$\begin{array}{l}\text { High-correlation } \\
\text { wind }\end{array}$ & 55.40 & 103.73 & 0.662 & 72.98 \\
$\begin{array}{l}\text { Low-correlation } \\
\text { wind }\end{array}$ & 52.97 & 103.73 & 0.668 & 75.97 \\
Solar & 78.98 & 259.06 & 0.645 & 279.16 \\
\hline
\end{tabular}

Notes : The table reports the average price, average cost, avoided emissions rate, and cost effectiveness of a one megawatt hour ( $\mathrm{MWh}$ ) increase in wind or solar generation (see text for the definition of high-correlation and low-correlation wind. The model is simulated assuming no environmental policies. Each row reports a separate simulation. The average price is the weighted average price of electricity, using the generation of the wind or solar generator as weights. The average cost is computed assuming a discount rate of 11.5 percent and a capacity factor of 0.27 for wind and 0.18 for solar. The avoided emissions rate is the weighted average emissions rate of the highest-cost coal or natural gas generator in operation, using the wind or solar generation as weights. Cost effectiveness takes the difference between the average cost and average price and divides it by the avoided emissions rate.

Table 4

\begin{tabular}{lcccc}
\hline \multicolumn{4}{c}{ Investment by Technology and RPS Scenario } \\
\hline \hline & $(1)$ & $\begin{array}{c}(2) \\
\text { High-correlation } \\
\text { wind RPS }\end{array}$ & $\begin{array}{c}\text { Low-correlation } \\
\text { wind RPS }\end{array}$ & Solar RPS \\
\hline Technology & No policy & 0.00 & 0.00 & 0.00 \\
Coal (GW) & 0.00 & 4.57 & 4.57 & 3.70 \\
Natural gas (GW) & 5.95 & 3.11 & 0.00 & 0.00 \\
$\begin{array}{l}\text { High-correlation wind } \\
\text { (GW) }\end{array}$ & 0.00 & 0.00 & 3.11 & 0.00 \\
Low-correlation wind & 0.00 & 0.00 & 0.00 & 4.74 \\
(GW) & 0.00 & & & \\
Solar (GW) & & 0.00 & \\
\hline
\end{tabular}

Notes : The table reports the investment for each technology in GW of capacity. Each row in each panel corresponds to a separate simulation. In the first column there are no policies included, and in columns 2-4 there is an RPS for the corresponding technology that causes that technology to account for three percent of generation. 
Table 5

\begin{tabular}{lcccc}
\hline \multicolumn{4}{c}{ Long-run Market and Environmental Values } \\
\hline \hline & $\begin{array}{c}\text { Average price } \\
(\$ / \mathrm{MWh})\end{array}$ & $\begin{array}{c}\text { Average cost } \\
(\$ / \mathrm{MWh})\end{array}$ & $\begin{array}{c}\text { Avoided emissions } \\
\text { rate }\left(\text { tons } \mathrm{CO}_{2} / \mathrm{MWh}\right)\end{array}$ & $\begin{array}{c}\text { Cost effectiveness } \\
\left(\$ / \text { ton } \mathrm{CO}_{2}\right)\end{array}$ \\
$\begin{array}{l}\text { High-correlation } \\
\text { Wind }\end{array}$ & 48.23 & 107.23 & 0.483 & 43.03 \\
$\begin{array}{l}\text { Low-correlation } \\
\text { Wind }\end{array}$ & 46.02 & 107.24 & 0.491 & 44.00 \\
Solar & 73.79 & 269.62 & 0.592 & 233.74 \\
\hline
\end{tabular}

Notes : The table reports the average price, average cost, avoided emissions rate, and cost effectiveness for three technology-specific RPS scenarios. Each row reports the results of a separate simulaton, which are the same simulations as reported in Table 4. The average price is the generation-weighted average price received by generators of the corresponding technology. Average cost is the sum of capital costs and operations and maintenance costs for the new renewable generators divided by total discounted generation over the 23 years simulated in the model. The avoided emissions rate is the difference between annual emissions in the no-policy and RPS scenarios, divided by annual generation of the new renewable generators, where the no-policy case is the same as in column 1 of Table 4. Cost effectiveness is the difference between the annual social welfare in the no-policy and RPS scenarios, divided by the avoided emissions. 
Table 6

\begin{tabular}{|c|c|c|c|c|c|c|}
\hline \multicolumn{7}{|c|}{ Effects of Alternative Policies on Investment, Generation, Emissions, and Welfare } \\
\hline & No policy & Carbon price & $\begin{array}{c}\text { Clean } \\
\text { electricity } \\
\text { standard }\end{array}$ & RPS & $\begin{array}{l}\text { Production } \\
\text { subsidy }\end{array}$ & Feed-in tariff \\
\hline & (1) & $(2)$ & (3) & (4) & (5) & (6) \\
\hline & \multicolumn{6}{|c|}{$\underline{\text { Panel A: investment (GW) }}$} \\
\hline Coal & 0.00 & 0.00 & 0.00 & 0.00 & 0.00 & 0.00 \\
\hline Natural gas & 5.95 & 0.00 & 15.12 & 1.11 & 1.22 & 1.45 \\
\hline Wind (high) & 0.00 & 0.00 & 0.10 & 6.37 & 7.26 & 6.30 \\
\hline \multirow[t]{2}{*}{ Wind (low) } & 0.00 & 0.00 & 0.00 & 4.00 & 5.40 & 6.30 \\
\hline & \multicolumn{6}{|c|}{ Panel B: 2018 generation (million MWh) and electricity price (\$/MWh) } \\
\hline Coal & 110.07 & 100.53 & 93.02 & 104.14 & 103.73 & 103.63 \\
\hline Natural gas & 120.15 & 108.87 & 148.55 & 96.50 & 97.47 & 98.00 \\
\hline Wind (high) & 0.00 & 0.00 & 0.00 & 16.09 & 18.33 & 16.09 \\
\hline Wind (low) & 0.00 & 0.00 & 0.00 & 10.30 & 13.84 & 15.98 \\
\hline \multirow[t]{2}{*}{$\begin{array}{l}\text { Average price } \\
(\$ / \mathrm{MWh})\end{array}$} & 63.22 & 87.91 & 50.33 & 67.52 & 60.03 & 60.62 \\
\hline & \multicolumn{6}{|c|}{ Panel C: emissions, welfare, and cost effectiveness } \\
\hline $\begin{array}{l}\text { Emissions (billion } \\
\text { tons } \mathrm{CO}_{2} \text { ) }\end{array}$ & 4.01 & 3.70 & 3.70 & 3.70 & 3.70 & 3.70 \\
\hline Welfare (billion \$) & 499.02 & 495.89 & 493.90 & 485.36 & 478.57 & 482.46 \\
\hline $\begin{array}{l}\text { Cost Effectiveness } \\
\text { (\$ per ton } \mathrm{CO}_{2} \\
\text { avoided) }\end{array}$ & & 10.11 & 16.67 & 44.47 & 66.58 & 53.64 \\
\hline $\begin{array}{l}\text { Notes: Each colum } \\
\text { Panel B reports anr } \\
\text { emissions and welf } \\
\text { in the correspondir } \\
\text { investment, solar } \mathrm{g} \\
\text { scenario in which t } \\
\text { ton. In column } 3 \text { th } \\
10 \text { percent RPS tha } \\
\text { MWh to all renewa } \\
\text { tax is imposed on }\end{array}$ & $\begin{array}{l}\text { ports result } \\
\text { generation } \\
\text { over the } 23 \\
\text { cenario and } \\
\text { ration, or } n \\
\text { are no car } \\
\text { ean electric } \\
\text { edits all win } \\
\text { s. In column }\end{array}$ & $\begin{array}{l}\text { rom a differen } \\
\text { technology in } \\
\text { ears of the sim } \\
\text { le no-policy cas } \\
\text { lear investmen } \\
\text { n policies. In co } \\
\text { standard requ } \\
\text { and solar equal } \\
\text { there is a feed }\end{array}$ & $\begin{array}{l}\text { cenario. Par } \\
\text { ear } 11 \text { in mil } \\
\text { ation. Cost } \mathrm{e} \\
\text { divided by } \mathrm{t} \\
\mathrm{n} \text { any of the } \\
\text { umn } 2 \text { there } \\
\text { es } 15 \text { percen } \\
\text { In column } \\
\text { tariff of } \$ 1\end{array}$ & $\begin{array}{l}\text { reports ir } \\
\mathrm{MWh} \text {. PaI } \\
\text { veness is } \\
\text { ference } \\
\text { arios. Co } \\
\text { arbon dic } \\
\text { clean el } \\
\text { e is a prc } \\
\text { per MW }\end{array}$ & $\begin{array}{l}\text { ment by tec } \\
\text { reports cum } \\
\text { difference b } \\
\text { hissions. The } \\
1 \text { reports th } \\
\text { emissions t } \\
\text { city. In colun } \\
\text { tion subsidy } \\
\text { all renewab } \\
\text { in tariff. }\end{array}$ & $\begin{array}{l}\text { lology in GW. } \\
\text { lative } \\
\text { ween welfare } \\
\text { is no solar } \\
\text { baseline } \\
\text { of } \$ 37.95 \text { per } \\
4 \text { there is a } \\
\$ 71.93 \text { per } \\
\text { s. A lump-sum }\end{array}$ \\
\hline
\end{tabular}


Figures:

Figure 1. Unregulated Market Equilibrium

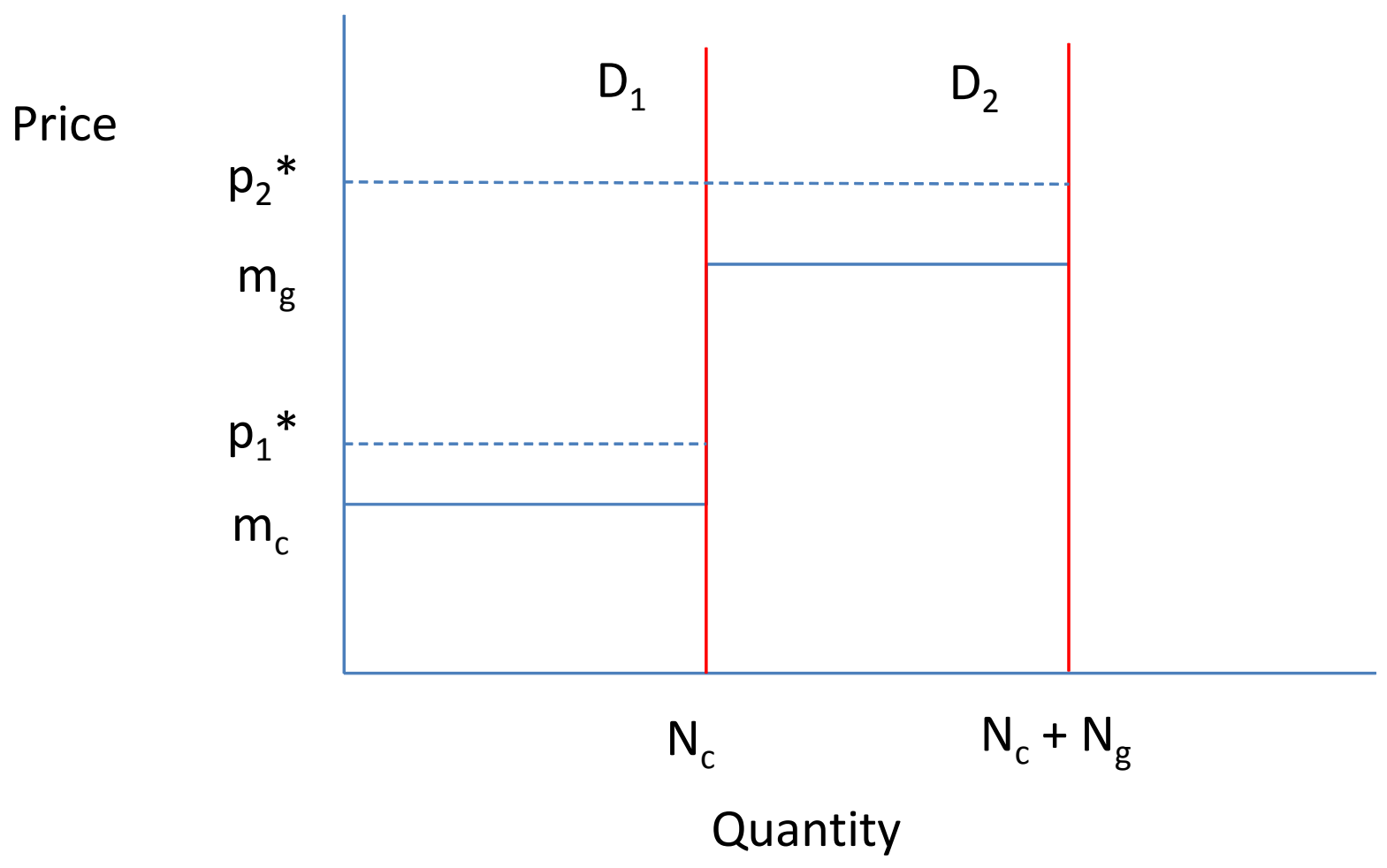


Figure 2a. Effect of Adding Wind Capacity

Price

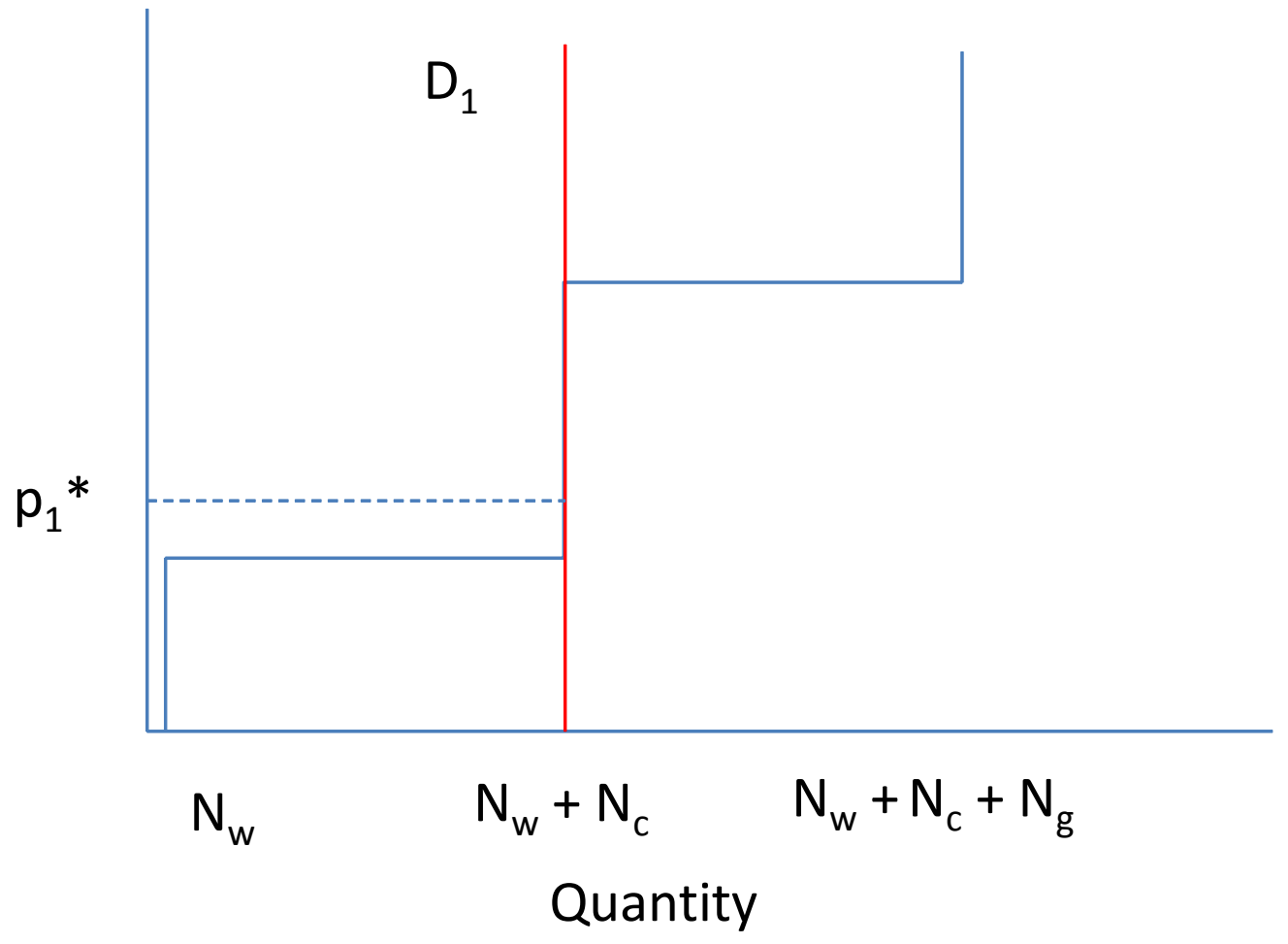

Figure 2b. Effect of Adding Solar Capacity

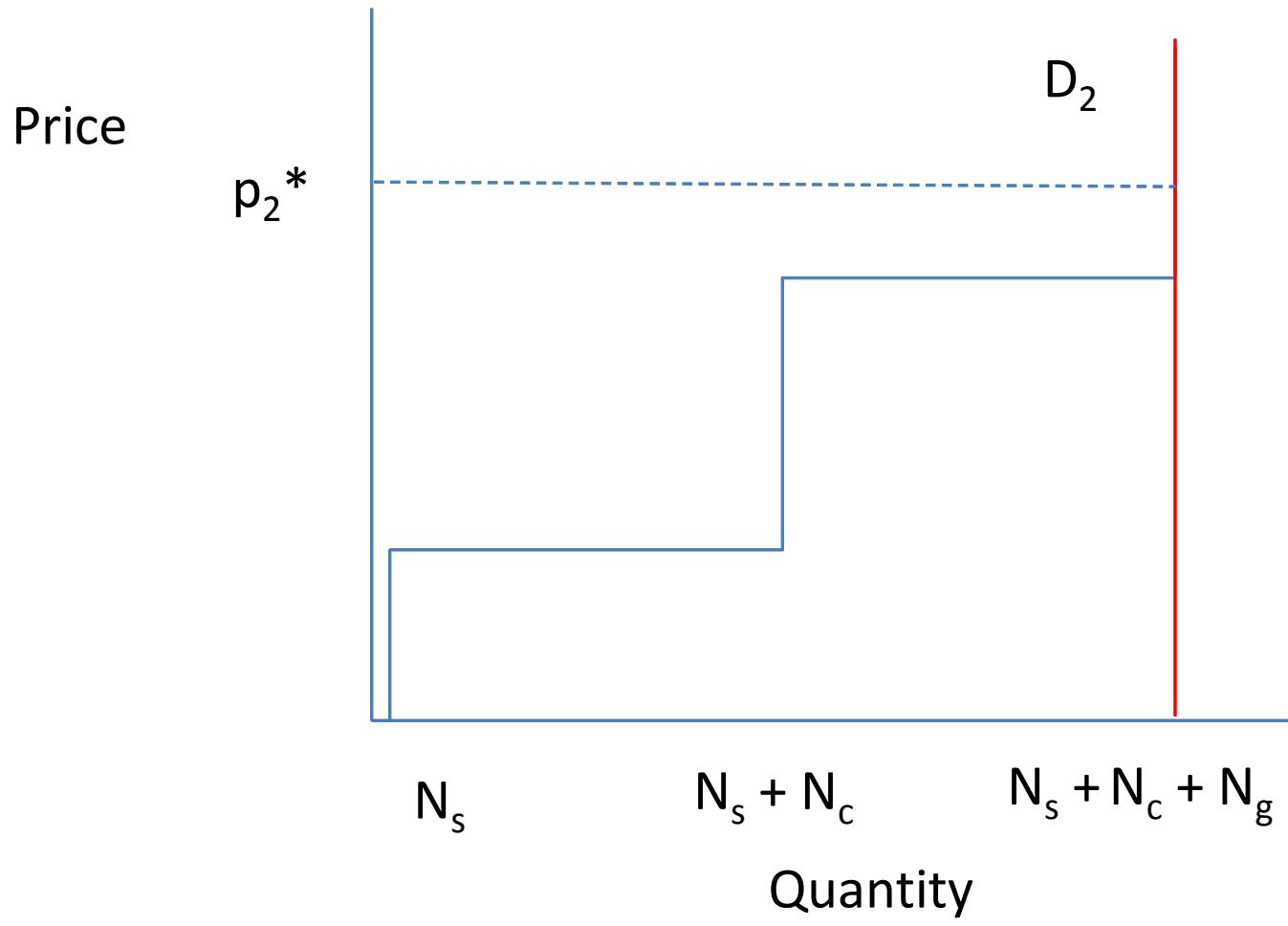


Figure 3. Equilibrium with a $\mathrm{CO}_{2}$ Emissions Price
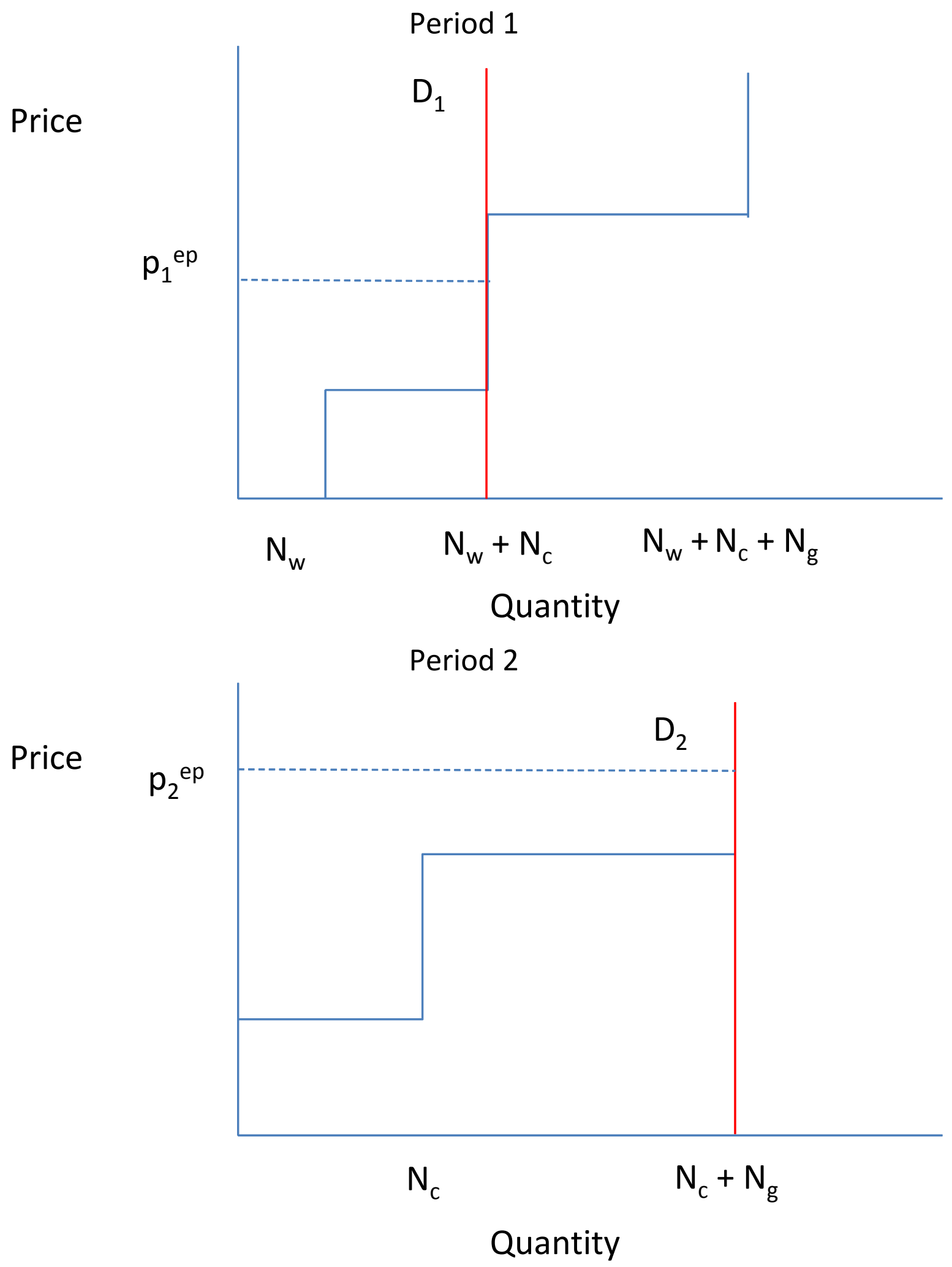
Figure 4. Equilibrium with an RPS
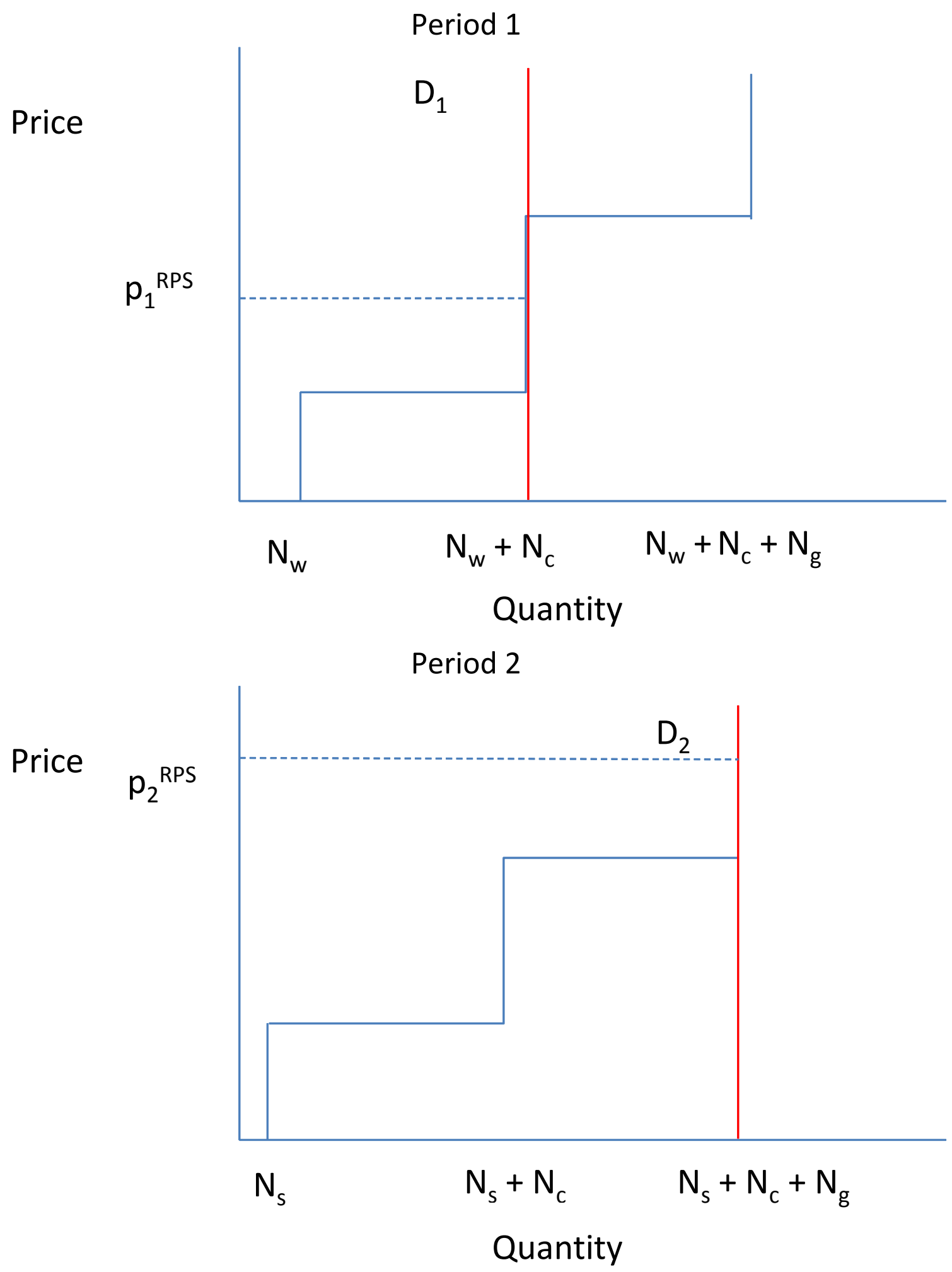